\title{
Article \\ Application of Computational Fluid Dynamics (CFD) in the Deposition Process and Printability Assessment of 3D Printing Using Rice Paste
}

\author{
Timilehin Martins Oyinloye ${ }^{1}$ and Won Byong Yoon ${ }^{1,2, * \mathbb{D}}$ \\ 1 Department of Food Science and Biotechnology, College of Agriculture and Life Sciences, Kangwon National \\ University, 1 Kangwondaehak-gil, Chuncheon 24341, Gangwon, Korea; oyinloyetm@kangwon.ac.kr \\ 2 Elder-Friendly Research Institute, Kangwon National University, 1 Kangwondaehak-gil, \\ Chuncheon 24341, Gangwon, Korea \\ * Correspondence: wbyoon@kangwon.ac.kr
}

check for

updates

Citation: Oyinloye, T.M.; Yoon, W.B. Application of Computational Fluid Dynamics (CFD) in the Deposition Process and Printability Assessment of 3D Printing Using Rice Paste. Processes 2022, 10, 68. https:// doi.org/10.3390/pr10010068

Academic Editors: Maximilian Lackner and Antonino Recca

Received: 15 November 2021 Accepted: 27 December 2021 Published: 29 December 2021

Publisher's Note: MDPI stays neutral with regard to jurisdictional claims in published maps and institutional affiliations.

Copyright: (c) 2021 by the authors. Licensee MDPI, Basel, Switzerland. This article is an open access article distributed under the terms and conditions of the Creative Commons Attribution (CC BY) license (https:// creativecommons.org/licenses/by/ $4.0 /)$

\begin{abstract}
Computational fluid dynamics (CFD) was utilized to investigate the deposition process and printability of rice paste. The rheological and preliminary printing studies showed that paste formed from rice to water ratio (100:80) is suitable for 3D printing (3DP). Controlling the ambient temperature at $47 \pm 5{ }^{\circ} \mathrm{C}$ also contributed to improving the printed sample's structural stability. The viscoelastic simulation indicated that the nozzle diameter influenced the flow properties of the printed material. As the nozzle diameter decreased $(1.2 \mathrm{~mm}$ to $0.8 \mathrm{~mm})$, the die swell ratio increased (13.7 to $15.15 \%)$. The rise in the swell ratio was a result of the increasing pressure gradient at the nozzle exit $\left(5.48 \times 10^{6} \mathrm{~Pa}\right.$ to $\left.1.53 \times 10^{7} \mathrm{~Pa}\right)$. The additive simulation showed that the nozzle diameter affected both the residual stress and overall deformation of the sample. CFD analysis, therefore, demonstrates a significant advantage in optimizing the operating conditions for printing rice paste.
\end{abstract}

Keywords: 3D printing; rice paste; computational fluid dynamics; additive manufacturing simulation; residual stress; die swell

\section{Introduction}

Three-dimensional printing (3DP), also known as additive manufacturing (AM), is a technique that integrates material and computer science, numerical control technology, and precision delivery [1-3]. The application of AM to food was begun using the digital control of the extrusion component in the printer to build up material deposition layer by layer based on computer-aided design (CAD) file [3]. Several studies have attempted to adapt AM technology to a variety of food products, such as wheat, corn starch, lemon juice gel, potato starch with pea protein, and cereal food [3-5]. However, major challenges and complex applications of food AM are emerging in the food sector, such as residual stress formation at the deposited layers, material properties' changes in the printing chamber as a result of shear stress, and die swell effect at the nozzle tip, amongst others which play a significant role in the stability or deformation of the final printed object $[5,6]$.

Many studies have evaluated how the AM of food materials could be adjusted to suit the desired purposes by probing material properties such as rheological and thermal properties, printing process parameters such as nozzle dimensions and shapes, and by comparing the printed food product with the designed model. For example, the printability of cereal grains was evaluated by computational fluid dynamics (CFD) simulation with rheological experiments, including viscoelastic measurement [7]. However, the success of the food AM is dependent not only on food material properties, deposition process, and printability, but also on postextrusion conditions such as extruded paste expansion due to die effect, rapid change in material properties due to heat transfer from the surrounding environment, and solidification process of extruded paste which can cause deformation to the lower layers of the printed object [3]. 
A quick way to solve AM problems is to visualize changes during the extrusion process. However, changes such as die swell may be invisible to the eye, and the closed AM environment may make assessment difficult [3]. In food extrusion, CFD simulations provide efficient methods to characterize the fluid behavior inside the extruder and after deposition is completed [5]. The study of Guo et al. [5] successfully analyzed the extrusion process for mashed potato in a syringe-based and screw-based extruder. The finite element method (FEM) was also used to analyze the stress and total deformation in printed alginate with pea protein gel [1]. However, there are still limited studies available evaluating the deposition process and postprinting process of food materials.

Rice (Oryza sativa) is a staple meal for about half of the globe, accounting for $20 \%$ of worldwide dietary energy consumption [8]. Rice flour has been widely used in various meals in recent decades, including infant formulas, gluten-free diets, rice noodles, etc., due to its significant nutritional and health benefits [9-11]. Rice dough has been described as a non-Newtonian fluid with high shear-thinning behavior and rheological properties comparable to weak gel and wheat dough, both of which have been successfully utilized in AM [12-14]. Researchers have also highlighted that AM of rice flour and rice starch is achievable by studying the AM precision, printing efficiency, texture properties, and changing the printing variables, i.e., nozzle size, perimeters, layer height, and infill density $[10,15]$ However, there are few research papers on the postextrusion and postdeposition process of AM for food products, especially rice.

Therefore, this paper aimed to explore the printability of rice paste, focusing on the rheological properties' changes in the printing chamber and the postextrusion effect on the sample, such as die swell and deformation of the sample because of the selected printing parameters and conditions, i.e., nozzle size, moisture content, and printing environment temperature. Furthermore, a CFD model was developed, and the simulation was conducted to predict the flow behavior of rice paste in a printer chamber, including the product deformation.

\section{Materials and Methods}

\subsection{Preparation of Rice Paste}

Commercial rice powder with a moisture content of $15.3 \%$ (w.b.) was purchased at the local market, Chuncheon, South Korea. The material for AM was prepared by mixing rice powder with water at the ratio of 100:60, 100:70, 100:80, 100:90, and 100:100. Because of the fast retrogradation induced by the high starch content, AM and rheological characterization were performed immediately after sample preparation. In addition, the sample temperature $\left(27 \pm 2{ }^{\circ} \mathrm{C}\right)$ was maintained in the printer chamber to remove the effect of increasing elastic properties due to high temperature in the chamber. Table 1 shows the moisture content of the rice paste samples.

Table 1. Moisture content of AM material.

\begin{tabular}{cc}
\hline Sample Ratio (Rice to Water) & Moisture Content (\%) \\
\hline $100: 60$ & $49.68 \pm 0.23^{\mathrm{a}}$ \\
$100: 70$ & $56.21 \pm 0.16^{\mathrm{b}}$ \\
$100: 80$ & $62.03 \pm 0.19^{\mathrm{c}}$ \\
$100: 90$ & $68.14 \pm 0.13^{\mathrm{d}}$ \\
$100: 100$ & $74.05 \pm 0.21^{\mathrm{e}}$ \\
\hline
\end{tabular}

Means \pm SD with superscript letters $(\mathrm{a}, \mathrm{b}, \mathrm{c}, \mathrm{d}$, and e) are significantly different at $p<0.05$.

\subsection{Preliminary Experiment}

A single-factor experimental design was conducted to understand the effect of moisture content on the printability of the rice paste. The printing conditions for the preliminary experiment were set based on the report of Liu et al. [10]. The printing conditions set were as follows: travel speed $20 \mathrm{~mm} / \mathrm{s}$, initial layer thickness $0.3 \mathrm{~mm}$, shell thickness $1.52 \mathrm{~mm}$, layer height $0.76 \mathrm{~mm}$, nozzle size $0.76 \mathrm{~mm}$, and infill density $100 \%$. Because of the printer's 
limited extrusion force, it is important to maintain a specific degree of viscosity by changing the paste concentration. To support the next printed layer, an appropriate concentration level that maintains acceptable extrusion properties and mechanical strength was chosen and utilized for further study.

\subsection{Rheological Properties of Rice Paste}

Rheological evaluation of rice paste was performed on a Discovery Hybrid Rheometer HR-3 (TA Instruments, New Castle, DE, USA) with a cone and plate geometry (cone diameter $40 \mathrm{~mm}$, cone angle $2^{\circ}$ ) [3]. The gap was set to $2 \mathrm{~mm}$ and the temperature was $27{ }^{\circ} \mathrm{C}$. The elastic modulus $\left(\mathrm{G}^{\prime}\right)$ and loss modulus $\left(\mathrm{G}^{\prime \prime}\right)$ were evaluated using dynamic oscillation frequency analysis in the range of $0.1-100 \mathrm{rad} / \mathrm{s}$ at a strain value of $0.04 \%$ within the identified linear viscoelastic region (LVR). The viscosity was analyzed as a function of shear rate, ranging from $0.1-100(1 / \mathrm{s})$.

\subsection{Thermal Properties of Rice Paste}

The differential scanning calorimetry (DSC) profiles of different ratios of rice paste were measured using a Discovery Series DSC (TA Instruments, New Castle, DE, USA) according to Shand et al. [16]. Approximately 10-15 $\mathrm{mg}$ of each paste was preweighed and hermetically sealed into an aluminum pan and heated from $20-100{ }^{\circ} \mathrm{C}$ with a heating rate of $5{ }^{\circ} \mathrm{C} / \mathrm{min}$. Nitrogen was used as a purge gas with a flow rate of $50 \mathrm{~mL} / \mathrm{min}$. The peak transition temperature or gelation temperature $\left(\mathrm{T}_{\mathrm{g}}\right)$, and enthalpy of gelation $(\Delta \mathrm{H})$, were computed from the endothermic peaks observed in the thermograms using computer software (Trios software v5.0.0 TA instruments, New Castle, DE, USA). The $\Delta H$ values were reported in $\mathrm{J} / \mathrm{g}$ starch, and each sample was analyzed in triplicate.

\subsection{Additive Manufacturing of Rice Paste}

The extrusion-based printing of rice paste was modified based on the method described in Liu et al. [10]. A printer with syringe-fused deposition modeling (SHINNOVE-S2, Shinnove Co. Ltd., Hangzhou, Zhejiang, China) was equipped with a nozzle diameter of $0.8,1.0$, or $1.2 \mathrm{~mm}$. The preliminary experiment resulted in the selection of standard material printing conditions. A box shape of product geometry $(\mathrm{H}=20 \mathrm{~mm}, \mathrm{~B}=20 \mathrm{~mm}$, and $\mathrm{L}=20 \mathrm{~mm}$ ) for the printing was created using Comsol multiphysics ${ }^{\circledR}$ version 3.5 (Comsol Inc., Burling, MA, USA) (Figure 1b). During AM, the extrusion temperature of rice paste was kept at $(27 \pm 2 \mathrm{C})$, while the printing environment temperature, i.e., the air around the extrudate, was maintained at an average of $47 \pm 5^{\circ} \mathrm{C}$, which was supplied by a heater with an airflow rate $(0.5 \mathrm{~m} / \mathrm{s})$. This has no effect on the sample structure. The base and environment temperatures were monitored using a noncontact infrared thermometer (RIDGID Micro IR-200, RIDGID tool company, Elyria Ohio, USA) and multiple thermocouples (DHT11 sensor) operated by Arduino UNO at the deposit-layer edge (printer plate) and the AM environment wall made of acrylic (Figure 1a). The printing percentage (a measurement of the printed model's completeness) and the shape fidelity of the printed product were used to assess printability under conventional printing settings. 
(a)

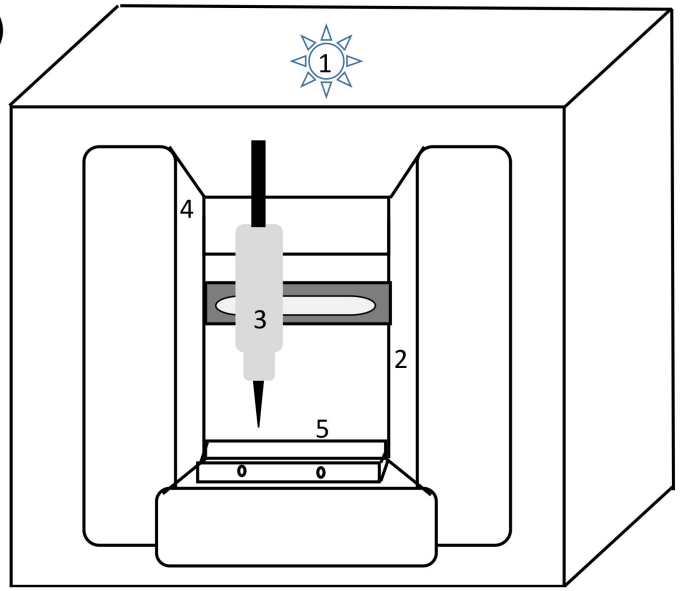

(b)

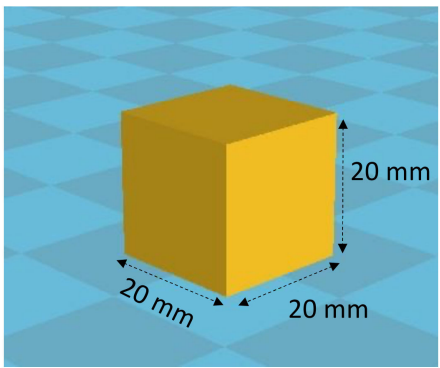

Figure 1. Schematic of the AM system, showing (a) heater position (1) and sensor position (2-5), and (b) the geometry of the printed product.

\subsection{Mathematical Model}

\subsubsection{FEM Simulation for Viscoelastic Fluid}

Viscoelastic flow simulation corresponding to the syringe-based AM was carried out using FEM-based software Polyflow module 2020 R2 (Ansys, Inc., Canonsburg, PA, USA). The simulation was conducted with only the optimum ratio of rice paste in this study. The computational domain was limited only to the nozzle and part of the syringe (sample chamber) to reduce the computational time, with a length of $50 \mathrm{~mm}$ from the nozzle tip. The geometry for the viscoelastic flow simulation (Figure 2a) was built with Ansys workbench 2020 R2 (Ansys, Inc., Canonsburg, PA, USA). A tetrahedral mesh was used to discretize the fluid domain in the geometry (Figure 2b). By using the gradient grid technique with splitting the geometry, high-quality grids were obtained. In the fluid area, the total number of elements was 5418. The task was set as steady-state and isothermal, and the material property data was entered. The boundary conditions were set as follows: input equals inlet, and the volume flow rate $\left(2.5 \times 10^{-8} \mathrm{~m}^{3} / \mathrm{s}\right)$ was used to match the value for the printing experiments. Subsequently, the elastic swell ratio $\left(E_{S}\right)$ of the extrudate was defined as the ratio of the material diameter $\left(\mathrm{M}_{\mathrm{D}}\right)$ to the nozzle diameter $\left(\mathrm{N}_{\mathrm{D}}\right)$ after extrusion stabilized (Equation (1)) [3]:

$$
\mathrm{E}_{\mathrm{s}}=\frac{\mathrm{M}_{\mathrm{D}}}{\mathrm{N}_{\mathrm{D}}}
$$

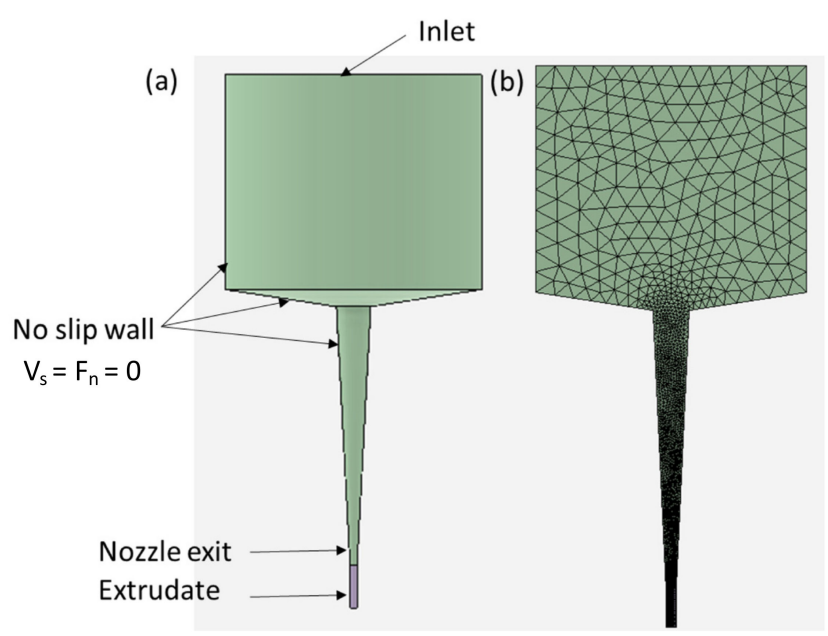

Figure 2. A schematic diagram of the printer nozzle and sample chamber, showing: (a) the flow domain's essential boundary conditions and (b) the mesh of the convergent region, as well as the nozzle exit. 


\subsubsection{Establishment of Flow Models and Assumptions}

The rice paste was thought to be an incompressible single-phase fluid with laminar flow, and the non-Newtonian behavior was defined and fitted by the power-law model (Equation (2)) [17]:

$$
\eta=\mathrm{K} \dot{\gamma}^{n-1}
$$

where $\eta$ is the viscosity $(\mathrm{Pa}), \mathrm{K}$ is the consistency index $\left(\mathrm{Pa}^{\mathrm{n}} \mathrm{s}^{\mathrm{n}}\right), \mathrm{n}$ is the flow behavior index and $\dot{\gamma}$ is the shear rate. To solve the governing conservation equations, the following continuity and momentum conservation equations in vector notation were applied:

$$
\begin{aligned}
\nabla \cdot \bar{v} & =0 \\
\rho\left(\frac{\partial v}{\partial \mathrm{t}}+\bar{v} \cdot \nabla v\right) & =-\nabla \mathrm{p}+\nabla \cdot \overline{\bar{\tau}}
\end{aligned}
$$

where $\bar{v}$ denotes the velocity vector, $\rho$ denotes the material density, p denotes the hydrostatic pressure, and $\overline{\bar{\tau}}$ denotes the extra stress tensor. The effect of gravity was ignored because of the material's high viscosity [18]. The stress tensor $(\mathrm{Pa})$ is described by the following constitutive equation [19]:

$$
\sigma=2 \eta \mathrm{D}
$$

where $\eta$ is shear-dependent non-Newtonian viscosity, while $\mathrm{D}$ is the rate of deformation tensor of fluid dependent on shear rate, which obeys the form

$$
\mathrm{D}=\frac{\nabla v+\nabla v^{\mathrm{T}}}{2}
$$

where $\nabla v$ and $\nabla v^{\mathrm{T}}$ are velocity gradient and the transpose of velocity gradient separately. In addition, the following assumptions and initial and boundary conditions related to flow characteristics of rice paste are used: (1) the paste is entirely in the chamber, (2) there is no slip between the material and the channel wall during the extrusion process, and (3) the paste was initially at rest, i.e., the initial paste velocity was $0 \mathrm{~mm} / \mathrm{s}$.

\subsubsection{Deposition Process Simulation and Boundary Conditions}

The deposition process of rice paste (100:80) was carried out using FEM-based software Additive Suite 2020 R2 (Ansys, Inc., Canonsburg, PA, USA). The fluid is extruded from the nozzle diameter onto a fixed solid surface. At time $t=0$, the extrusion nozzle is at rest, and at time $t>0$, the material starts to flow through the nozzle with a fully developed profile. To evaluate the deposition process, the thermal properties (thermal resistivity, thermal conductivity, and specific heat) are measured with the KS-1 sensor in the KD2 Pro device (Decagon Devices, Inc., Pullman, WA, USA) and the elastic properties of the rice paste at the printing temperature are required. The model geometry was built with Ansys workbench 2020 R2, and it includes a part geometry (printed product) and base geometry (printing bed) along the Z-direction (Figure 3). A support geometry was created between the part and base geometry with the FEM software (Figure 3). A Cartesian mesh the same size as the nozzle diameter was generated for all geometry. The build conditions were preheat temperature set as $27^{\circ} \mathrm{C}$ (paste temperature), and the deposit thickness set as the nozzle diameter $(0.8,1.0$, or $1.2 \mathrm{~mm})$. The postprinting conditions were environment temperature of $47^{\circ} \mathrm{C}$, and the removal of generated support material for the structural analysis. The heat transfer coefficient was not explicitly specified, but the effects of conduction and convection are calculated via the built-in momentum and nonlinear heat-balance equations:

$$
\rho c \frac{\partial \mathrm{T}}{\partial \mathrm{t}}=\frac{\partial \mathrm{T}}{\partial \mathrm{x}}\left(\mathrm{k} \frac{\partial \mathrm{T}}{\partial \mathrm{x}}\right)+\frac{\partial}{\partial \mathrm{y}}\left(\mathrm{k} \frac{\partial \mathrm{T}}{\partial \mathrm{y}}\right)+\frac{\partial}{\partial \mathrm{z}}\left(\mathrm{k} \frac{\partial \mathrm{T}}{\partial \mathrm{z}}\right)+\mathrm{Q}_{\mathrm{v}}
$$

where $\rho$ is the density, $c$ is the specific heat, $T$ is the temperature, $t$ is the time, $k$ is the thermal conductivity, and $Q_{V}$ is the volumetric heat flux. 


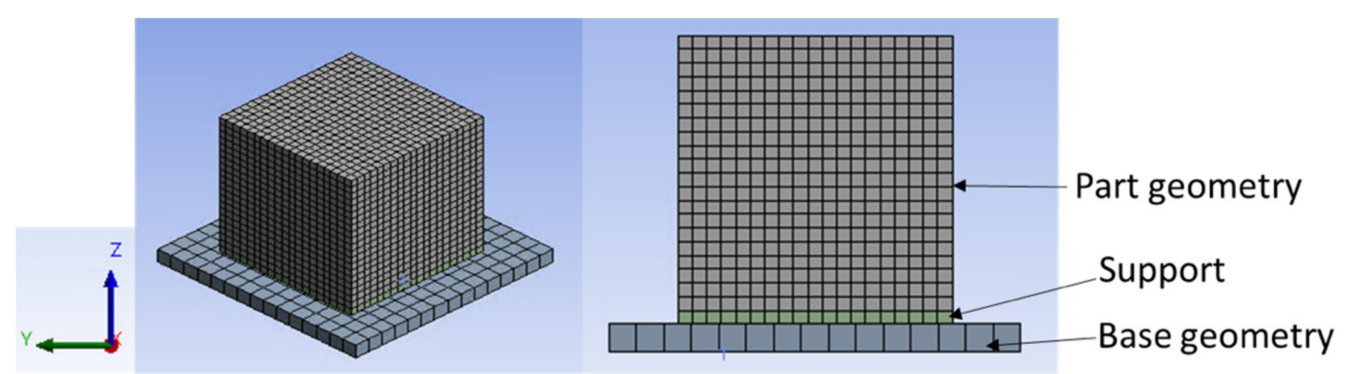

Figure 3. A schematic diagram of the rice paste printing model.

For the transient thermal simulation, the base material (printing bed) and filler materials (rice paste) were considered homogeneous and isotropic, but the thermophysical parameters, i.e., $k, c$, and $\rho$ are functions of the sample and the temperature. The simulation was conducted in transient mode using the built-in coupled solver and third-order discretization schemes. Finally, the produced transient thermal analysis result stored within the nodes for different time frames was transferred to the static structure for the analysis of stress characteristics. The governing equation for the stress model is

$$
\delta_{\mathrm{ij}} \mu \sigma=0
$$

where $\sigma$ is the stress, $\mu$ is the Poisson's ratio, and $\delta_{\mathrm{ij}}$ is the Kronecker tensor. The total strain $\varepsilon_{\mathrm{ij}}$ tensor consists of three parts: elastic strain $\varepsilon_{\mathrm{ij}}^{\mathrm{e}}$, plastic strain $\varepsilon_{\mathrm{ij}}^{\mathrm{p}}$, and thermal expansion strain $\varepsilon_{\mathrm{ij}}^{\mathrm{th}}$, as follows:

$$
\varepsilon_{\mathrm{ij}}=\varepsilon_{\mathrm{ij}}^{\mathrm{e}}+\varepsilon_{\mathrm{ij}}^{\mathrm{p}}+\varepsilon_{\mathrm{ij}}^{\mathrm{th}}
$$

The $\varepsilon_{\mathrm{ij}}^{\text {th }}$ at temperature $\mathrm{T}$ was calculated by

$$
\varepsilon_{\mathrm{ij}}^{\text {th }}=\alpha_{\mathrm{e}} \Delta \mathrm{T}=\alpha_{\mathrm{e}}\left(\mathrm{T}-\mathrm{T}_{\text {ref }}\right)
$$

where $T_{\text {ref }}$ is the reference temperature, and $\alpha_{\mathrm{e}}$ is the linear coefficient relating the rate at which strain changes with a unit change in temperature. The constitutive model of the total stress $\sigma_{\mathrm{ij}}$ and elastic strain $\varepsilon_{\mathrm{hk}}^{\mathrm{e}}$ is

$$
\sigma_{\mathrm{ij}}=\mathrm{C}_{\mathrm{ijhk}} \varepsilon_{\mathrm{hk}}^{\mathrm{e}}
$$

where $C_{i j k}$ is the fourth-order elasticity tensor as a function of the elastic modulus $E$ and Poisson's ratio v.

\section{Elastic Properties of Rice Paste}

The elastic properties of the rice paste were determined using the method described by Miri et al. [20] with slight modifications. A shear test was conducted at 25, 40, and $60{ }^{\circ} \mathrm{C}$ using the Discovery Hybrid Rheometer HR-3 with a plate and parallel geometry ( $40 \mathrm{~mm}$ in diameter). The testing gap was set as $2 \mathrm{~mm}$, and the paste was allowed to rest on the plate geometry for $10 \mathrm{~min}$ before testing. To avoid moisture loss, the sample was covered with a vapor trap. A digital caliper (Mitutoyo Corporation, Kwasaki, Kanagawa, Japan) measured the final thickness and diameter. The tensile stress was measured over a strain range of 0.5 to $500 \%$. Because the sample relaxes during the testing, imposing constant normal stress enhanced the consistency of the shear modulus results. The slope of the regression line of shear stress vs. shear strain up to $5 \%$ was used to derive the shear modulus. Using Equations (12)-(14), the bulk modulus, Poisson's ratio, and Young's modulus were calculated, respectively [21]:

$$
\begin{gathered}
\mathrm{B}=\frac{\text { Bulk stress }}{\text { Bulk strain }}=\frac{\mathrm{F} / \mathrm{A}}{-\Delta \mathrm{V} / \mathrm{v}_{0}} \\
\mu=\frac{\text { Lateral strain }}{\text { Linear strain }}=\frac{\varepsilon_{\text {lateral }}}{\varepsilon_{\text {linear }}}=\frac{\Delta \mathrm{D} / \mathrm{D}}{\Delta \mathrm{L} / \mathrm{L}} \\
\mathrm{E}=2 \mathrm{G}(1+\mu)
\end{gathered}
$$


where $\mathrm{B}$ denotes the bulk modulus, $\mathrm{F}$ denotes force, $\mathrm{A}$ denotes the sample area, $\Delta \mathrm{V}$ and $\mathrm{V}_{0}$ are the change in volume and the initial volume of the sample, respectively, $\Delta \mathrm{D}$ and $\mathrm{D}$ are the change in diameter and the initial diameter, $\Delta \mathrm{L}$ and $\mathrm{L}$ are the change in length and the initial length, respectively, $\mu$ is the Poisson's ratio, $G$ is the shear modulus, and $E$ is Young's modulus.

\subsection{Postextrusion Analysis}

The deposition process and shape fidelity of the final printed sample was analyzed using image processing tool in Matlab (Mathworks ${ }^{\circledR}$ Inc., Natick, MA, USA) [22]. The extrusion process of the rice paste was videotaped using a digital camera with an image resolution of $5184 \times 3888$ pixel (DSLR-500D, Canon Inc, Tokyo, Japan). The tape was converted to frame images. Five frames within 5 to $20 \mathrm{~s}$ of extrusion time were selected for analysis among the frame generated. Likewise, the final printed structure picture was captured within $5 \pm 1$ s of printing structure completion before moving the sample. The image processing steps include (1) conversion of videotape to frame, (2) image background extraction, (3) binarization, (4) object extraction, and (5) object length and width measurement [22]. Threshold-based segmentation (0.2) was used to separate the solid object from the background. The procedure for image processing to analyze the extruded rice paste is shown in Figure 4.

(a)

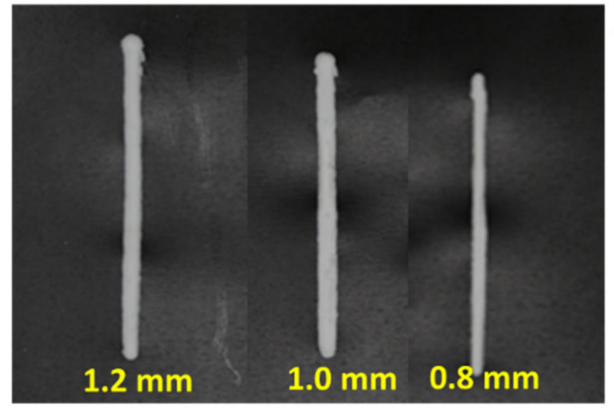

(c)

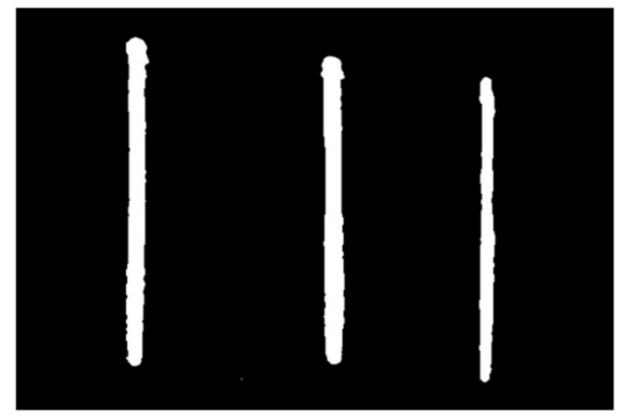

(b)

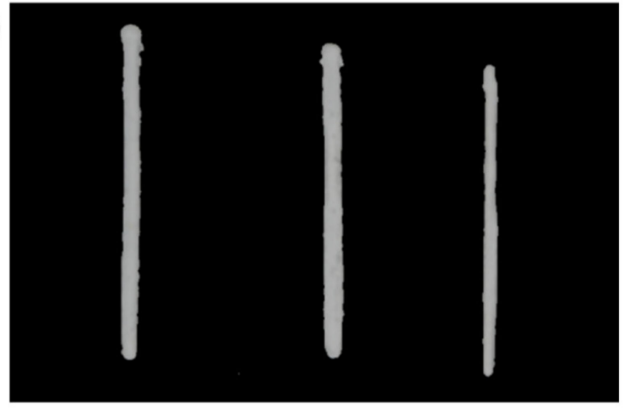

(d)

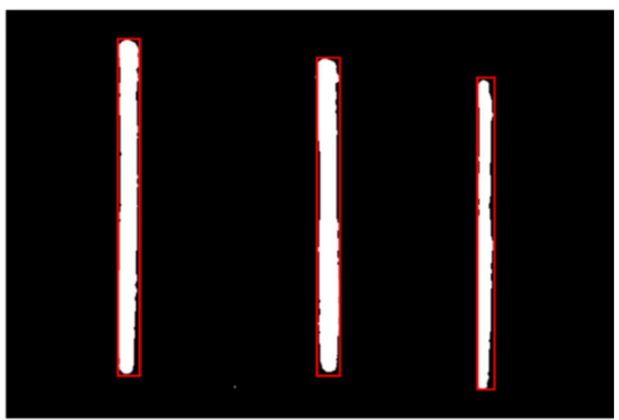

Figure 4. The image processing procedure for extruded rice paste: (a) frame image acquired from videotape, (b) background removal, (c) gray image generation, (d) bounding box formation.

\section{Result and Discussion}

\subsection{Rheological Properties of Rice Paste}

The apparent viscosity curve of the rice paste is shown in Figure 5. The viscosity decreased significantly with an increased shear rate. This indicated that the pastes are pseudoplastic fluid and shear-thinning liquid. The shear-thinning characteristic is beneficial because it allows the rice paste to become thinner when subjected to a higher shear force, resulting in the paste being able to flow out of a printing nozzle smoothly [23]. Notably, the apparent viscosity at a low shear rate indicated sample 100:60 to be about two times higher than the sample (100:70). Rice starch has a strong affinity to water; therefore, water around the rice molecules is rapidly absorbed, resulting in a dense network [24]. The parameters of the flow curve fitted by the power-law model describing the non-Newtonian pattern 
is shown in Table 2 [17]. The Newtonian behavior in rice paste progressively switched to shear-thinning with increased moisture content, with $n$ increasing from 0.3685 to 0.7074 . K value reflected the mixture's viscosity and increased from $3.51 \times 10^{3}$ to $1.55 \times 10^{6}$ Pa.s $^{\mathrm{n}}$, indicating that rice paste with a rice-to-water ratio of 100:60 may exhibit poor extrusion characteristics and may not be readily extruded out of the nozzle during printing.

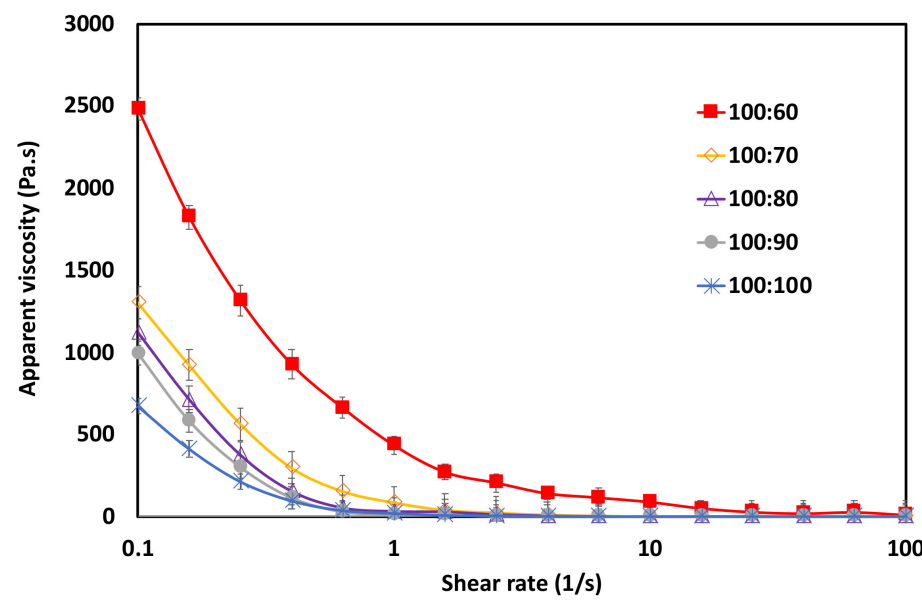

Figure 5. The apparent viscosity of rice paste at different mixture ratios.

Table 2. Fitted coefficient values of the power-law model of the rice paste.

\begin{tabular}{cccc}
\hline Sample (Rice: Water) & $\mathbf{K}\left(\mathbf{P a} \cdot \mathbf{s}^{\mathbf{n}}\right)$ & $\mathbf{n}$ & $\mathbf{R}^{2}$ \\
\hline $100: 60$ & $1.55 \times 10^{6}$ & 0.3685 & 0.9310 \\
$100: 70$ & $3.17 \times 10^{5}$ & 0.4534 & 0.9801 \\
$100: 80$ & $2.27 \times 10^{4}$ & 0.3395 & 0.9906 \\
$100: 90$ & $3.51 \times 10^{3}$ & 0.6205 & 0.9419 \\
$100: 100$ & $5.33 \times 10^{2}$ & 0.7074 & 0.9502 \\
\hline
\end{tabular}

The results of the storage modulus $\left(\mathrm{G}^{\prime}\right)$ (Figure 6a) and loss modulus $\left(\mathrm{G}^{\prime \prime}\right)$ (Figure 6b) of the rice paste are shown in Figure $6 . G^{\prime}$ and $G^{\prime \prime}$ showed a frequency dependence, with $\mathrm{G}^{\prime}$ greater than $\mathrm{G}^{\prime \prime}$ indicating a gel-like structure dominated by elastic behavior that is beneficial to shape-retention ability of a printed object [15]. A comparable outcome with $\mathrm{G}^{\prime}$ greater than $G^{\prime \prime}$ was reported for rice paste [10]. The $G^{\prime}$ and $G^{\prime \prime}$ increased gradually as the rice concentration increased, indicating the formation of a stronger mechanical strength. Consistent with other research, increasing starch concentration could make starch paste thicker, thus reducing its flowability $[25,26]$. Therefore, accurate rheological properties are needed to achieve a successful food printing; the higher the elastic properties, the higher the pressure force required to extrude the sample.
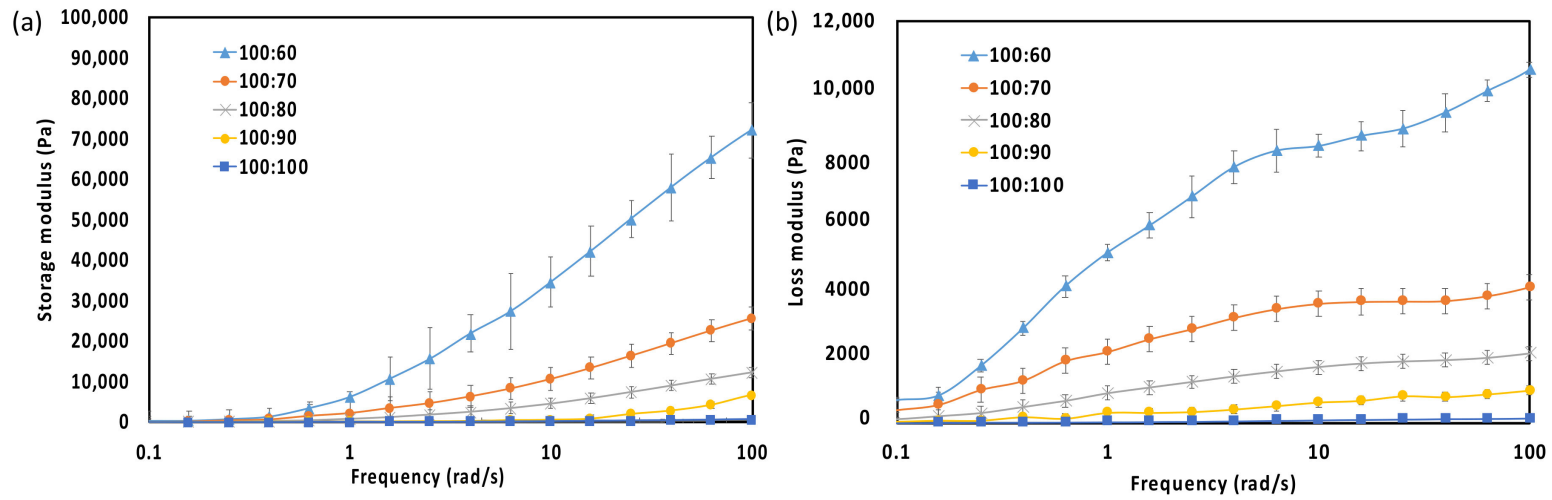

Figure 6. Dynamic rheological characteristics of rice paste with different mixture ratios. 


\subsection{Thermal Properties of Rice Paste}

The effect of moisture content on gelatinization characteristics in rice paste is shown in Figure 7 and Table 3. The DSC profile showed the presence of a single endothermic peak in each of the rice paste samples [11]. The onset of gelatinization was found between 48.6 and $59.7^{\circ} \mathrm{C}$ for all samples in the moisture content ranging from 49.68 to $74.05 \%$ (Figure 7 ). The peak gelatinization temperature ranged between 63.12 to $65.03{ }^{\circ} \mathrm{C}$ and was found to decrease insignificantly with a decrease in moisture content for all samples [27]. The presence of high moisture content encouraged lower-onset gelatinization temperature for the rice paste. The curves of samples 100:90 and 100:100 were almost overlapped before the rice flour was completely gelatinized, indicating that there was no significant difference in the gelation and thermal stability of the two mixture ratios due to the presence of high moisture content. In addition, the transition enthalpy $\left(\Delta \mathrm{H}_{\mathrm{g}}\right)$ analyzed from the area within the curve showed an increasing trend with a reduction in the rice concentration (Table 3 ). The increase in $\Delta \mathrm{H}_{\mathrm{g}}$ with moisture content has been reported by several authors [28,29]. The increase was reported to be linear until 60\% moisture content [29], reaching a constant value above $75 \%$ moisture level [28].

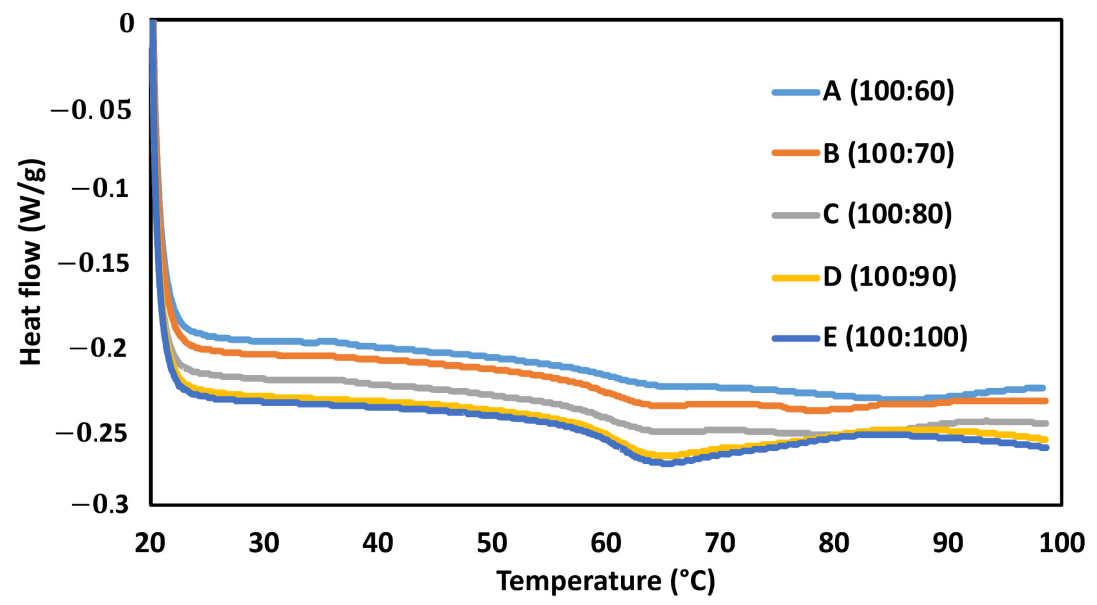

Figure 7. DSC thermograms for rice paste samples at different moisture ratios.

Table 3. Gelatinization temperature and enthalpy value.

\begin{tabular}{ccc}
\hline $\begin{array}{c}\text { Sample Ratio } \\
\text { (Rice: Water) }\end{array}$ & $\begin{array}{c}\text { Peak Gelatinization } \\
\text { Temperature }\left({ }^{\circ} \mathbf{C}\right)\end{array}$ & Enthalpy $\Delta \mathbf{H}_{\mathbf{g}}(\mathbf{J} / \mathbf{g})$ \\
\hline $100: 60$ & $65.03 \pm 0.85^{\mathrm{a}}$ & $129.11 \pm 1.51^{\mathrm{a}}$ \\
$100: 70$ & $64.09 \pm 1.24^{\mathrm{a}}$ & $133.60 \pm 2.12^{\mathrm{b}}$ \\
$100: 80$ & $63.99 \pm 1.07^{\mathrm{a}}$ & $137.75 \pm 0.69^{\mathrm{c}}$ \\
$100: 90$ & $63.77 \pm 1.43^{\mathrm{a}}$ & $136.78 \pm 1.02^{\mathrm{bc}}$ \\
$100: 100$ & $63.12 \pm 1.37^{\mathrm{a}}$ & $142.82 \pm 1.33^{\mathrm{e}}$ \\
\hline
\end{tabular}

Means \pm SD with superscript letters (a, b, c, and e) along same column are significantly different at $p<0.05$.

\subsection{Preliminary Experiment to Determine the Optimum Moisture Ratio for Rice Paste}

Printed samples from all mixture ratios are shown in Figure 8. The model structure was influenced by increasing moisture content (49.68 to $74.05 \% \mathrm{MC}$ ) due to the changing viscoelastic characteristics. The decrease in the elasticity and viscosity with increasing moisture content described in Figure 5 indicated softening of the internal structure which can be considered a dilution effect and is evident in the printed sample (Figure 8) [30]. The decreasing viscosity allows for easier extrusion of the rice paste but causes printed structures to collapse as the numbers of layers increases [31,32]. Surprisingly, sample 100:60 with significantly high viscosity had problems with extrusion, and the structure was not entirely printed. This occurred because the paste became clogged at the nozzle tip. Structural collapse, on the other hand, increased with increasing moisture content 
(Figure 8). Based on the rheological property and preliminary printing, it is clear that that the optimal mixture ratio for rice paste was sample 100:80 because it was easily extruded and was able to maintain the designed structure to an extent. Therefore, the mixture ratio of 100:80 was used for all other experiments.

Sample (100:60)

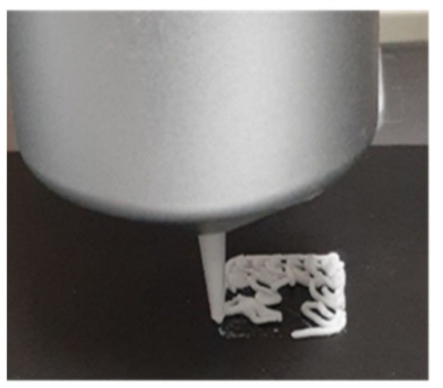

Sample (100:70)

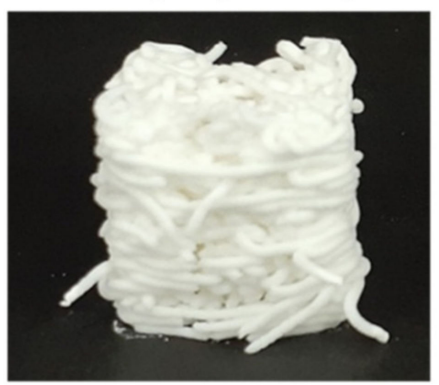

Sample (100:80)

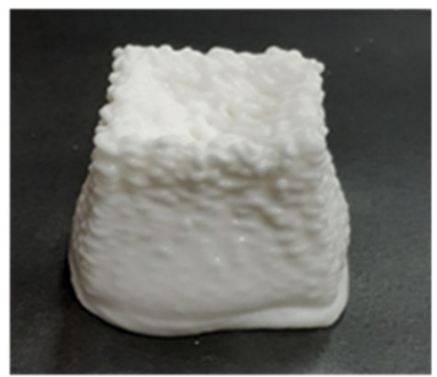

Sample (100:90)

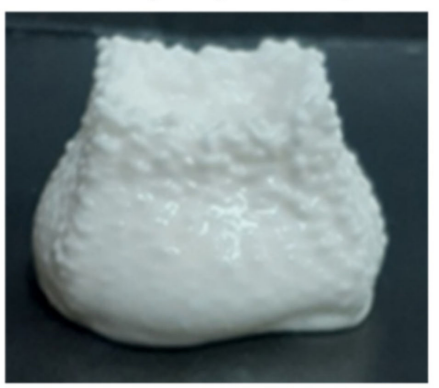

\section{Sample (100:100)}

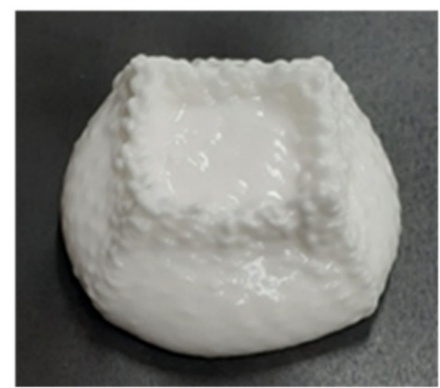

Figure 8. Preliminary printing of rice paste to determine optimum mixture ratio.

\subsection{Structural Stability and Slumping Behavior}

The influence of printing conditions on the structural collapse of rice paste $(100: 80)$ during the AM process is shown in Figure 9. The structural breakdown was typically seen beginning with the fifth printed layer (Figure 9a). This might be due to factors such as generated shear stress and weaker elastic characteristics. To avoid collapse during AM, the bottom layers must sustain the weight of the top layers without deforming; this necessitates that the printing material has appropriate viscoelastic characteristics. Liu et al. [33] correlated structural stability with yield stress, storage modulus, loss modulus, and ambient temperature. Additionally, the yield stress for alginate and pea protein increased with an increasing shear rate during AM [1]. As the paste is forced out of the nozzle exit, the yield stress increased with increasing pressure and shear rate and resulted in changes in the material's viscoelastic characteristics [34]. This led to slumping behavior.

In most situations, temperature control is necessary to drive the elastic characteristics of starch or hydrocolloids up to the level required to sustain all printed layers [10]. However, for starch, raising the sample temperature before printing produces extrudability problems. As a result, rice and rice starch are printed in paste form, and the printed structure is then heated to develop a gel [10]. The printing environment temperature was controlled to rapidly improve the elastic property of the extrudate as the structure layers were produced to manage the structure collapse (Figure 9b). The increasing temperature of the environment strengthens the surface starch model, which prevents the inner component of the starch from free-flowing due to its weaker elastic characteristics. The sample viscosity throughout a $5{ }^{\circ} \mathrm{C} / \mathrm{min}$ temperature sweep is shown in Figure 9c. The fast increase in sample viscosity from $51.56{ }^{\circ} \mathrm{C}$ demonstrates the paste top's gel-forming propensity. This finding is consistent with the gelation characteristics stated in Section 3.2. As a result, when the printing environment temperature was around $51.56{ }^{\circ} \mathrm{C}$, the surface starch of the extrudate became a gel state. 
(a)

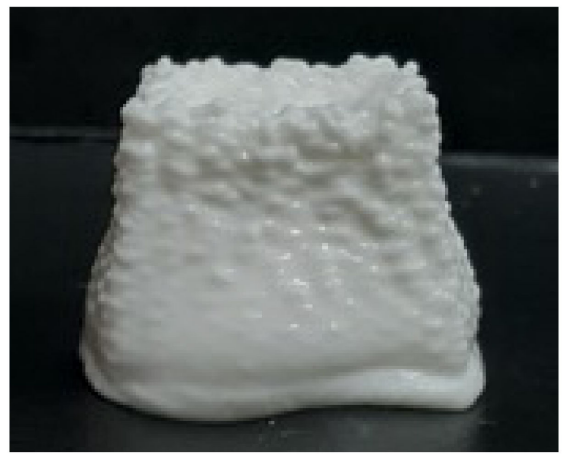

(b)
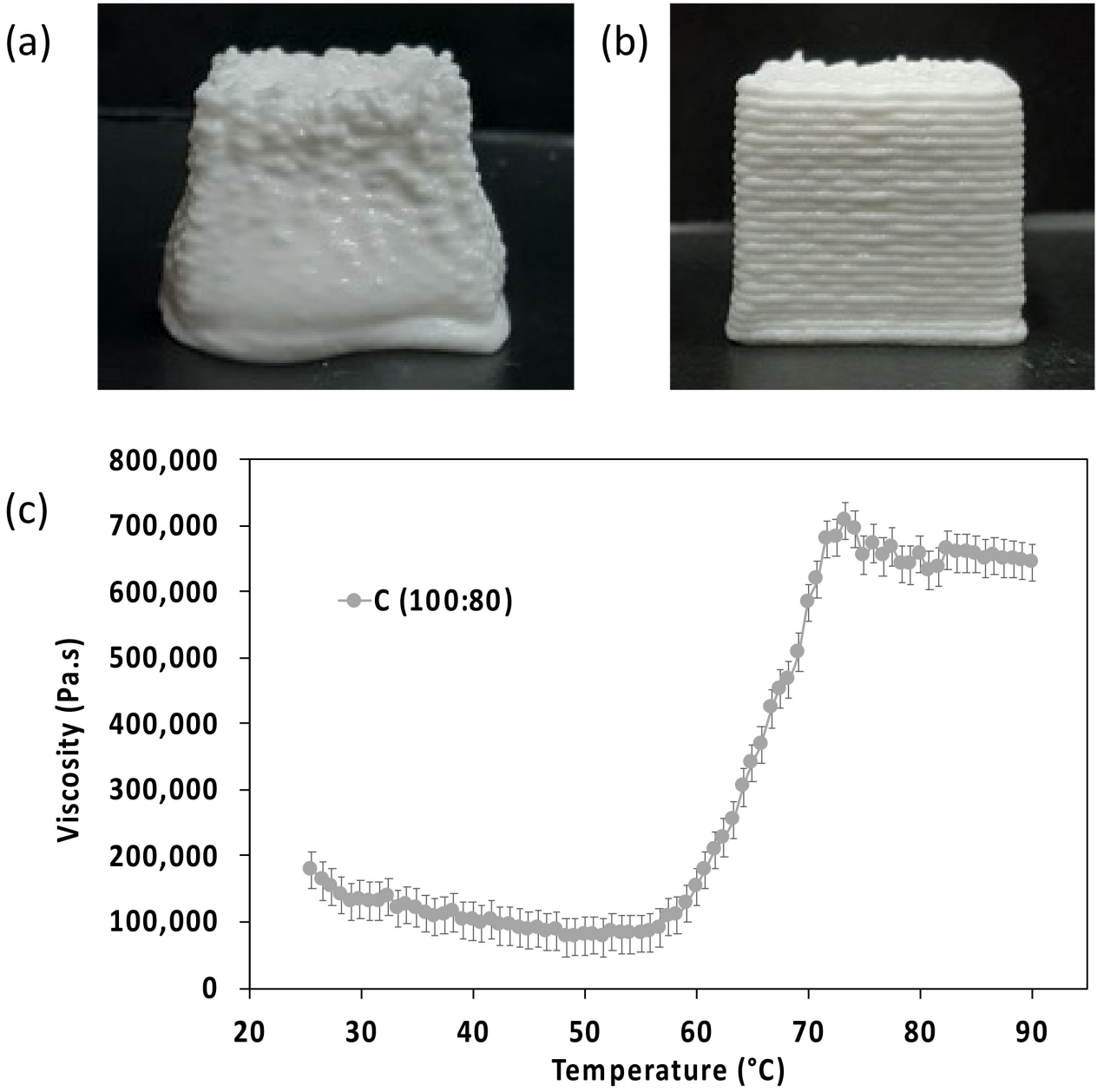

Figure 9. Structural stability of rice paste model: (a) sample printed at room temperature $\left(28^{\circ} \mathrm{C}\right)$, (b) sample printed at controlled printing temperature $\left(47 \pm 5^{\circ} \mathrm{C}\right)$, and (c) sample viscosity changes with increasing temperature.

\subsection{Estimation of Flow Field and Printing Precision}

\subsubsection{Local Shear-Rate Distribution}

The simulated local shear rates in the printer chamber and the extruded paste are shown in Figure 10. The local shear rates followed a similar pattern for all nozzle sizes and were relatively low in the syringe but rapidly rose in the nozzle and reached their peak at the nozzle exit. Because of the shear-rate differential between the chamber and the nozzle, the paste was subjected to a higher shear force at the nozzle wall, resulting in a considerable velocity gradient along the normal direction of the wall. The shear-rate value was nozzle diameter-dependent, with the smallest diameter $(0.8 \mathrm{~mm})$ yielding the highest shear rate in the nozzle $\left(952.75 \mathrm{~s}^{-1}\right)$. This value reduces as the nozzle diameter increases (i.e., $510.06 \mathrm{~s}^{-1}$, and $300.96 \mathrm{~s}^{-1}$, for nozzle diameter 1.0 and $1.2 \mathrm{~mm}$, respectively). This finding could be explained by a comparable flow rate and extrusion force being applied to the paste in the chamber; as a result, the pressure differential at the exit zone of each nozzle varies, with smaller nozzle diameters having a higher pressure gradient. This affected the observed shear rate at the nozzle exit. Furthermore, residual shear stress was observed in the extruded paste, and was found to be higher when printing with a bigger nozzle diameter. The high residual stress is associated with high flow rate. This may drastically alter the shape fidelity of the object as the nozzle diameter increases. 
(a)

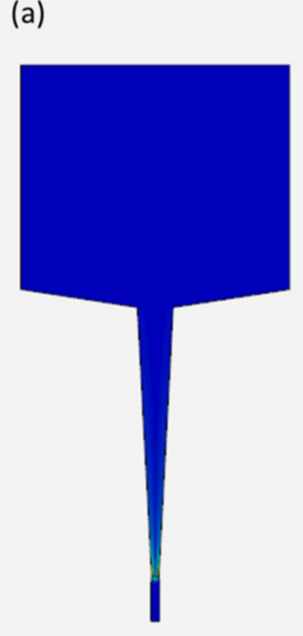

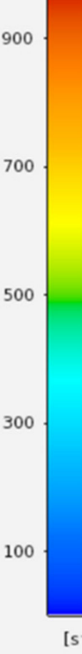

(b)

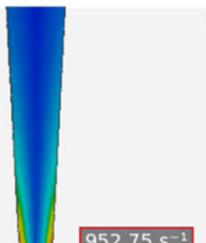

(c)

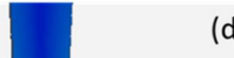

(d)

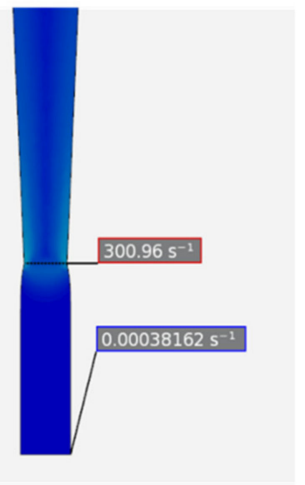

Figure 10. Simulated shear rate $(1 / \mathrm{s})$ distribution of the rice paste with different nozzle sizes: (a) fluid domain, (b) nozzle size $0.8 \mathrm{~mm}$, (c) nozzle size $1.0 \mathrm{~mm}$, and (d) nozzle size $1.2 \mathrm{~mm}$.

\subsubsection{Velocity Distribution}

The velocity profile of the rice paste extrusion process was a straightforward top-tobottom laminar flow (Figure 11). The velocity steadily rose near the nozzle entry region and increased towards the exit. Additionally, the velocity on the central axis was higher than that along the barrel wall on the same horizontal section, particularly in the nozzle region. Because the applied extrusion force was constant, the pressure at the nozzle exit region increased with a reduction in the diameter. Thus, the shrinkage of the nozzle increased the velocity around the nozzle exit and the velocity of the extruded paste; hence, the $0.8 \mathrm{~mm}$ nozzle diameter had the highest velocity value $\left(0.185 \mathrm{~ms}^{-1}\right)$ while the $1.2 \mathrm{~mm}$ nozzle had the lowest velocity value $\left(0.083 \mathrm{~ms}^{-1}\right)$. Given that the shear rates were not evenly distributed throughout the whole computational area (Section 3.5.1), it is logical to assume that the viscosities of the shear-thinning material would not be constant over the same region. Therefore, the material velocity on the central axis increased as the flow channel narrowed and remained constant in the extrudate (Figure 11).

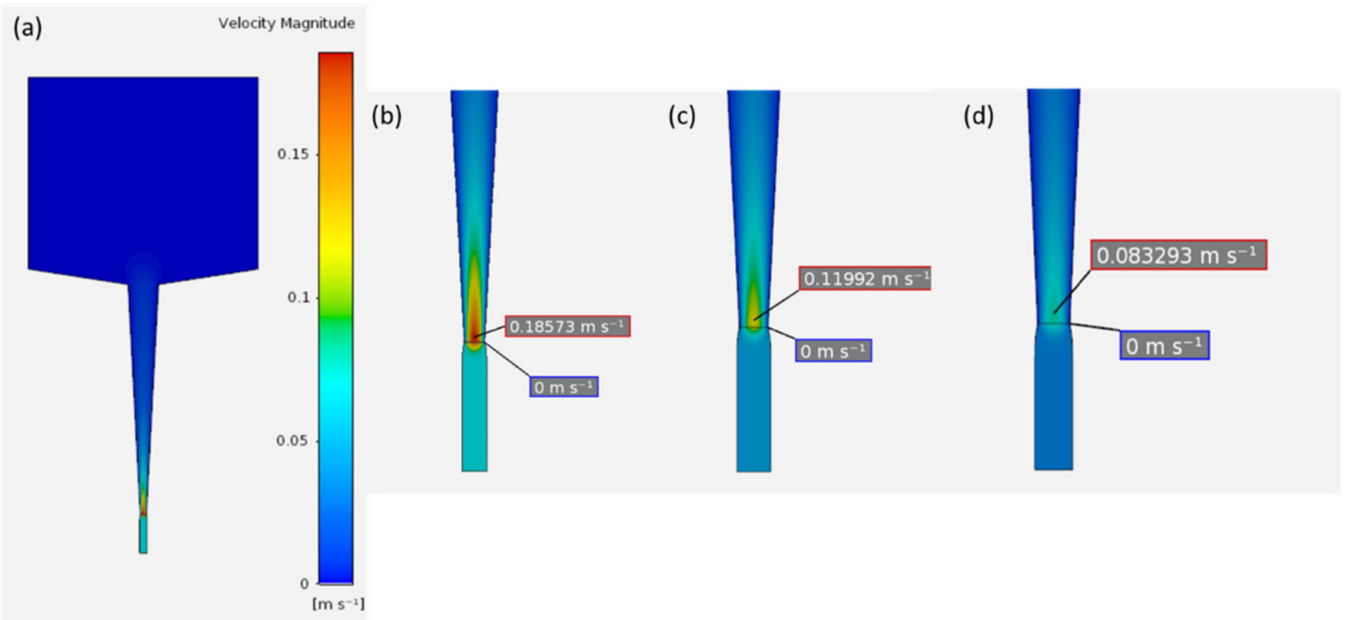

Figure 11. Velocity distribution of rice paste with different nozzle sizes: (a) fluid domain, (b) nozzle size $0.8 \mathrm{~mm}$, (c) nozzle size $1.0 \mathrm{~mm}$, and (d) nozzle size $1.2 \mathrm{~mm}$. 


\subsubsection{Pressure Distribution Field Analysis}

The pressure distribution in the printing chamber and the extruded paste are shown in Figure 12. A pressure gradient was created by the atmospheric pressure after the paste was extruded from the nozzle; thus, a negative pressure that increases with nozzle size was observed in the paste for all nozzle diameters $\left(-1.532 \times 10^{7} \mathrm{~Pa},-8.951 \times 10^{6} \mathrm{~Pa}\right.$, and $-5.485 \times 10^{6} \mathrm{~Pa}$ for nozzle size $0.8,1.0$, and $1.2 \mathrm{~mm}$, respectively). An increase in the nozzle diameter caused a decrease in the pressure in the nozzle entrance zone $\left(3.266 \times 10^{14} \mathrm{~Pa}\right.$, $1.772 \times 10^{14} \mathrm{~Pa}$, and $1.086 \times 10^{14} \mathrm{~Pa}$ for nozzle size $0.8,1.0$, and $1.2 \mathrm{~mm}$, respectively). This is because a bigger nozzle diameter facilitated paste flow and decreased the pressure gradient at the nozzle region. Pressure has an impact on the quality of 3D-printed items. When the pressure applied to the material was too low during the extrusion process, the material could not be extruded from the nozzle; and when too high, a different structure from the design was printed [35]. The variations in the extruded paste form induced by the die show the consequences of increased pressure near the nozzle tip [34].

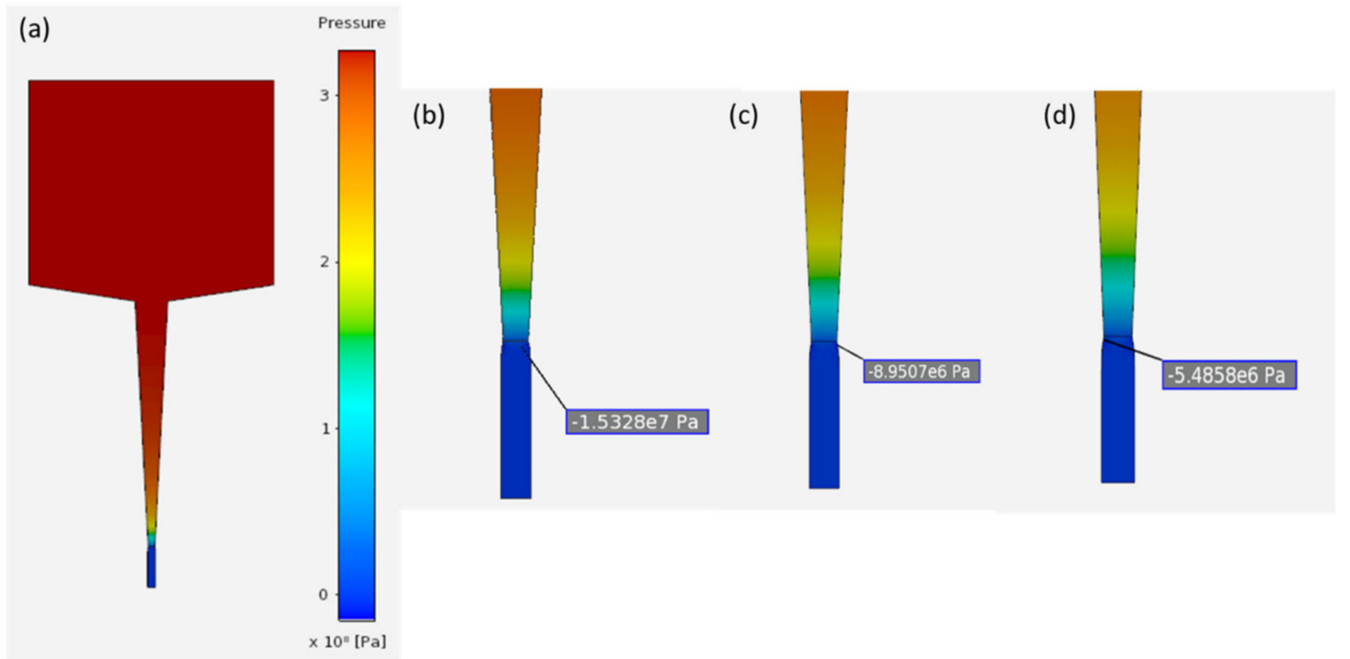

Figure 12. Pressure distribution of rice paste with different nozzle sizes: (a) fluid domain, (b) nozzle size $0.8 \mathrm{~mm}$, (c) nozzle size $1.0 \mathrm{~mm}$, and (d) nozzle size $1.2 \mathrm{~mm}$.

\subsubsection{Analysis of Die Swell Phenomena of Rice Paste Extrudate}

The variations in shape and size of the extrudate are shown in Figure 13. The die swell ratio increased as nozzle diameter decreased (13.73, 14.44, and 15.15\% for 1.2, 1.0, and $0.8 \mathrm{~mm}$, respectively) (Table 4). As the paste passes through the diameter contraction section, the viscous elastic fluid undergoes severe tensile deformation due to the die effect, storing part of the elastic potential energy. The elastic potential energy is fully released as the fluid exits the nozzle, resulting in extrudate swelling $[34,36]$. Although the magnitude of swelling of the extrudate is minimal and may not be visible, one must take precautions as it may significantly contribute to sample deformation during AM. This is because it accounts for some of the residual stress seen in extruded samples, and higher residual stress might result in fast structural deformation [36]. Rapid freezing, particularly for materials with a lengthy relaxation period (high viscosity) or rapidly rising temperature, has been used to manage this, allowing the residual stress to be controlled and progressively eliminated [36]. 

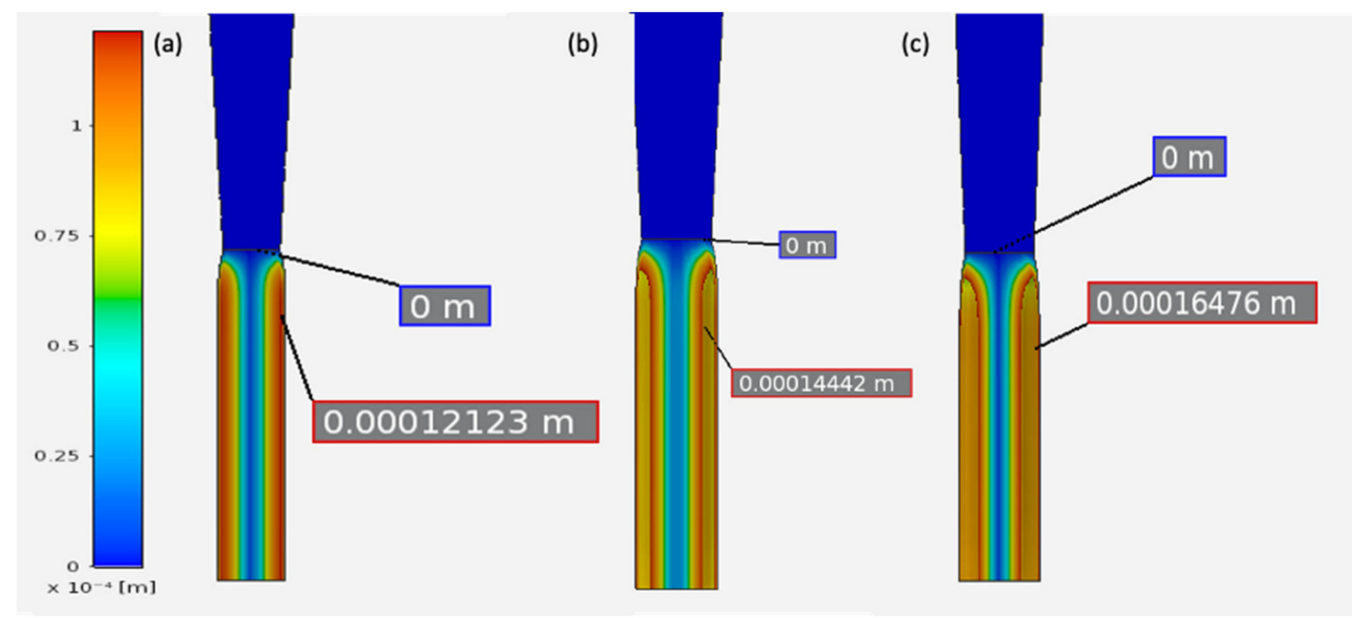

Figure 13. Die swell analysis of rice paste extrudate with different nozzle sizes: (a) nozzle size $0.8 \mathrm{~mm}$, (b) nozzle size $1.0 \mathrm{~mm}$, and (c) nozzle size $1.2 \mathrm{~mm}$.

Table 4. Swell ratio of rice paste as influenced by the nozzle diameter.

\begin{tabular}{cccc}
\hline & \multicolumn{3}{c}{ Nozzle Diameter (mm) } \\
\cline { 2 - 4 } & $\mathbf{0 . 8} \mathbf{~ m m}$ & $\mathbf{1 . 0} \mathbf{~ m m}$ & $\mathbf{1 . 2} \mathbf{~ m m}$ \\
\hline Image analysis result & $0.91 \pm 0.01^{\mathrm{a}}$ & $1.12 \pm 0.01^{\mathrm{b}}$ & $1.33 \pm 0.02^{\mathrm{c}}$ \\
Change in sample size (exp.) & 0.11 & 0.12 & 0.13 \\
Simulation extrudate width & 0.92 & 1.14 & 1.36 \\
Die swell ratio (\%) & 15.15 & 14.44 & 13.73 \\
\hline Means \pm SD with superscript letters (a, b, and c) along same row are significantly different at $p<0.05$.
\end{tabular}

3.5.5. Deposition Process of Rice Paste by Additive Manufacturing (AM) Simulation 3.5.5.1. Thermal and Elastic Properties Used during AM Simulation

The thermal and elastic properties of rice paste (100:80) measured at varying temperatures are presented in Tables 5 and 6, respectively. Thermal conductivity and specific heat decreased with increasing temperature. The thermal analysis result is similar to the value reported for rice flour [37]. On the other hand, the elastic properties of rice paste increased with increasing temperature, showing a reduction in the tendency to deform. The values recorded are close to the range reported for materials of biological origin [38]. Both the thermal and elastic properties were used to prepare the material data for the AM simulation.

Table 5. Thermal properties and density of 3D-printing rice paste material (sample 100:80).

\begin{tabular}{ccccccc}
\hline & \multicolumn{5}{c}{ Temperature $\left.{ }^{\circ} \mathrm{C}\right)$} \\
\cline { 2 - 7 } & $\mathbf{2 5}$ & $\mathbf{3 0}$ & $\mathbf{4 0}$ & $\mathbf{5 0}$ & $\mathbf{6 0}$ & $\mathbf{7 0}$ \\
\hline $\begin{array}{c}\text { Thermal conductivity } \\
\left(\mathrm{Wm}^{-1} \mathrm{~K}^{-1}\right)\end{array}$ & 0.398 & 0.345 & 0.293 & 0.107 & 0.067 & 0.032 \\
$\begin{array}{c}\text { Thermal resistivity } \\
\left(\mathrm{mKW}^{-1}\right)\end{array}$ & $251.78 \pm 0.001^{\mathrm{a}}$ & $264.1 \pm 0.009^{\mathrm{b}}$ & $311.3 \pm 0.001^{\mathrm{c}}$ & $366.4 \pm 0.001^{\mathrm{d}}$ & $411.8 \pm 0.002^{\mathrm{e}}$ & $489.5 \pm 0.002^{\mathrm{f}}$ \\
$\begin{array}{c}\text { Specific heat } \\
\left(\mathrm{JK}^{-1} \mathrm{Kg}^{-1}\right)\end{array}$ & 4.016 & 4.004 & 3.956 & 3.716 & 3.582 & 3.411 \\
Density $\left(\mathrm{Kgm}^{-3}\right)$ & 667.83 & 653.25 & 646.81 & 652.17 & 682.37 & 704.82 \\
\hline
\end{tabular}


Table 6. Elastic properties of rice paste (sample 100:80).

\begin{tabular}{cccc}
\hline & \multicolumn{3}{c}{ Temperature $\left({ }^{\circ} \mathrm{C}\right)$} \\
\cline { 2 - 4 } & $\mathbf{2 5}$ & $\mathbf{4 0}$ & $\mathbf{6 0}$ \\
\hline Shear modulus $(\mathrm{Pa})$ & 46.42 & 188.49 & 1688.2 \\
Young's modulus $(\mathrm{Pa})$ & 201.1533 & 801.0825 & 6752.8 \\
Bulk modulus $(\mathrm{Pa})$ & $1.6 \times 10^{-4}$ & $2.0 \times 10^{-4}$ & $2.6 \times 10^{-4}$ \\
Poisson's ratio & 1.16 & 1.13 & 0.99 \\
\hline
\end{tabular}

\subsubsection{Printing Process at Preheat Temperature (Simulation)}

The simulation model for the sample (100:80) printed at preheat temperature $\left(27 \pm 2{ }^{\circ} \mathrm{C}\right)$ is illustrated in Figure 14. Similar to the observation made during the preliminary experiment (Figure 9a), the rice paste printed suffered a higher deformation $\left(>7.29 \times 10^{6}\right)$ after several layers were printed on each other. As discussed in Section 3.4, factors such as residual shear stress and weaker elastic characteristics might be responsible for the structural deformation. Therefore, the printing environment temperature was adjusted to the onset of gelatinization temperature for rice paste described in Section $3.2\left(51.2^{\circ} \mathrm{C}\right)$. The rising environment temperature will influence the elastic properties of the surface molecules as each layer is formed.

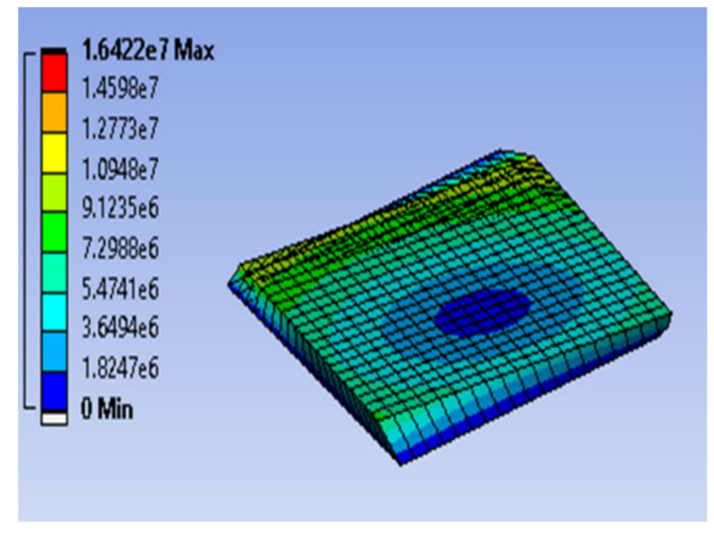

Figure 14. Total deformation in an uncontrolled environment temperature.

\subsubsection{Simulated Result of Thermal Analysis}

The thermal analysis conducted for various nozzle diameters $(0.8,1.0$, and $1.2 \mathrm{~mm})$ are shown in Figure 15. The printing phases (i.e., buildup and cooling phase, Figure 15a) are dependent on the nozzle diameter. The buildup phase (point B in Figure 15a) indicated the printing period, and it took a total of $288.62,389.94$, and $550.51 \mathrm{~s}$ to complete the printing phase for 1.2, 1.0, and $0.8 \mathrm{~mm}$ nozzle diameter size, respectively, before the onset of the cooling phase (indicated as point $C$ in Figure 15a). As the printing phase progresses, the average model temperature decreases at a rate influenced by the nozzle diameter. Firstly, the decreasing temperature was a result of the temperature distribution from the surface of the printed layers towards the center portion of the model in the form of conduction heat transfer. Secondly, a comparable heating rate was found for all nozzle sizes until around $68.3 \mathrm{~s}$ of the printing phase; following this period, a varying heat transfer rate that increased with increasing nozzle diameter was recorded. The initial comparable heat transfer rate recorded for all nozzle sizes might be influenced by the printing bed temperature because of direct contact. Subsequently, the changes in the temperature transfer rate may be attributed to the larger surface area of each of the printed layers and is affected by both conduction and convection heat transfer mechanisms. The higher surface temperature of the model aids in improving the viscoelastic characteristics of rice paste by initiating the gelatinization process, enhancing model firmness, and preventing center paste from free-flowing due to gravity. 
(a)

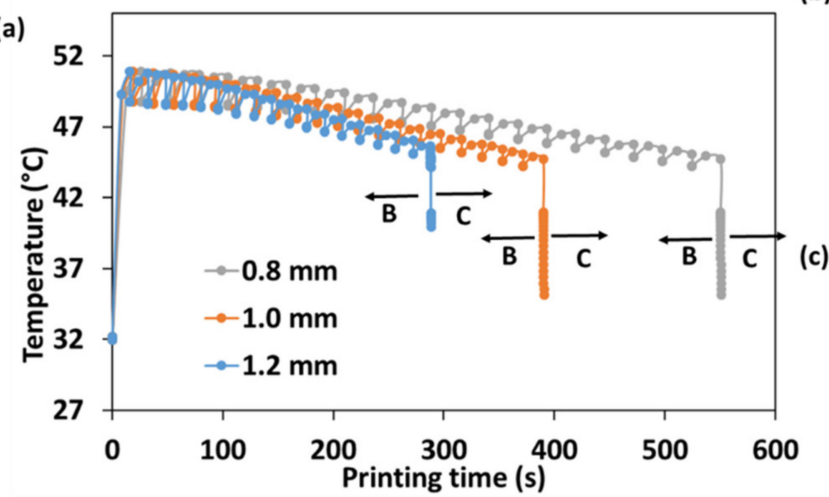

(b)

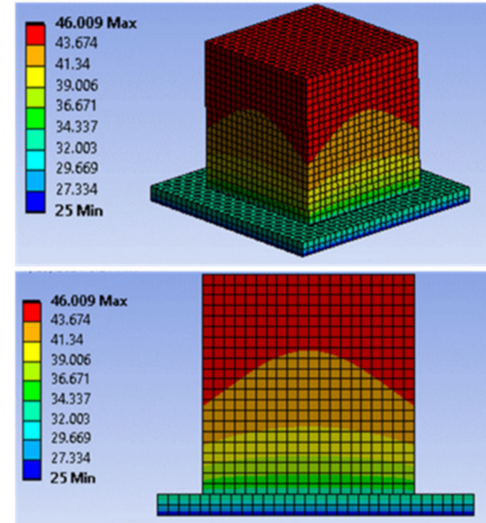

Figure 15. Simulated temperature distribution for the additive 3DP for rice paste (100:80): (a) topview component structure after the buildup phase, and (b) sideview component structure after the buildup phase (c).

\subsubsection{Simulated Stress Distribution during AM Process}

The result of the residual stress at different nozzle diameters is shown in Figure 16. The extrudate had residual tensile stress before the paste touched the printing bed $(3 \pm 1 \mathrm{~s}$ into the printing phase). The same stress value was observed within $14 \pm 3 \mathrm{~s}$ for all nozzle diameters (Figure 16). This was the time required to complete the first layer, and because this layer was directly resting on the printing bed, the stress value was only affected by the shear rate at the nozzle tip and not the layer-stacking process. Subsequently, the structures printed with nozzle sizes 0.8 and $1.0 \mathrm{~mm}$ showed increased stress value which could result from a smaller passage area for the extruded paste. However, after about two or three layers were printed, the stress in the structure printed with a nozzle diameter of $1.2 \mathrm{~mm}$ increased sharply. This may be attributed to the high flow rate and short printing time providing limited time for the relaxation and surface gelatinization of extruded paste. Thus, the layers might not rest properly on each other. In addition, the stress developed during the printing process showed an increased value with increasing nozzle diameter. However, it could be seen that the printed products with nozzle diameters 0.8 and $1.0 \mathrm{~mm}$ had similar stress values, especially towards the completion process. The reason for this is not well known, but it is thought to have been as a result of a close shear rate value at the nozzle tip. However, for nozzle diameter $1.2 \mathrm{~mm}$, the higher stress value was attributed to the high extrusion rate and limited printing time.

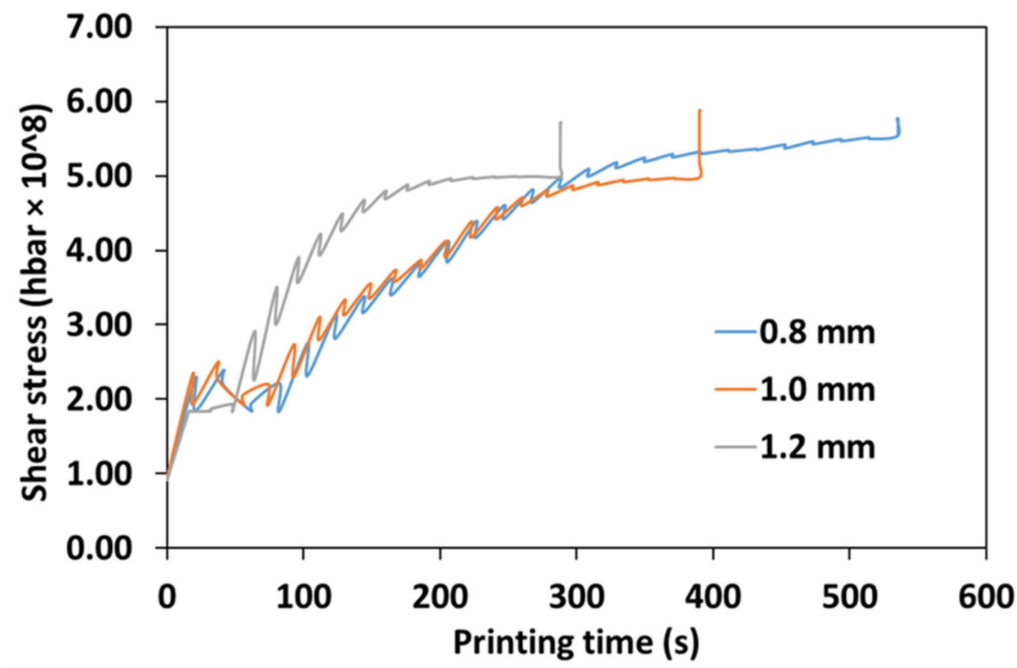

Figure 16. Simulated result of stress distribution during the printing process of rice paste based on nozzle size. 


\subsubsection{Deformation Analysis in the Printed Sample}

The deformation in the Z-direction during and after the AM is shown in Figure 17. The residual stress within the sample influenced the total deformation in the printed product. The product printed with a nozzle diameter of $0.8 \mathrm{~mm}$ showed substantially greater deformation (0.001) from the beginning of the printing phase until $178.3 \mathrm{~s}$ into the printing phase, after which a steady increase in deformation rate was observed. The significant deformation at the start of the printing phase may be attributed to the die swell effect. As a result, the first few printed layers for the structure showed a significant deviation from the design (Figure 17a). As the printing process progressed, the paste gained heat from its environment, and the viscoelastic properties were improved, thus preventing model deformation such that the $0.8 \mathrm{~mm}$ nozzle diameter did not exceed 0.002 with additional layers (Figure 17a).

(a)

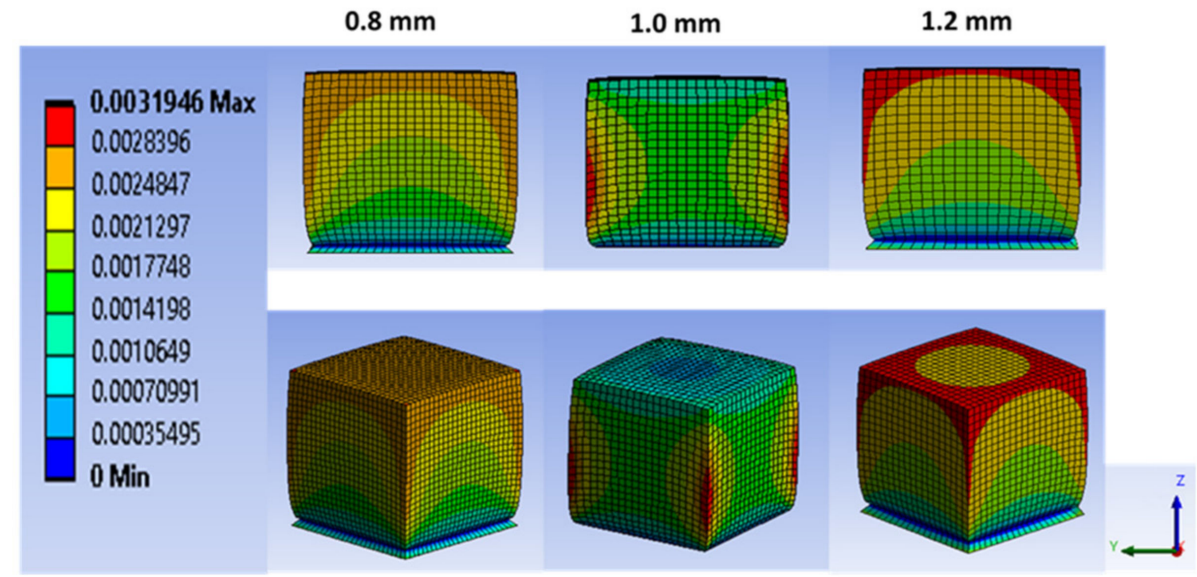

(b)

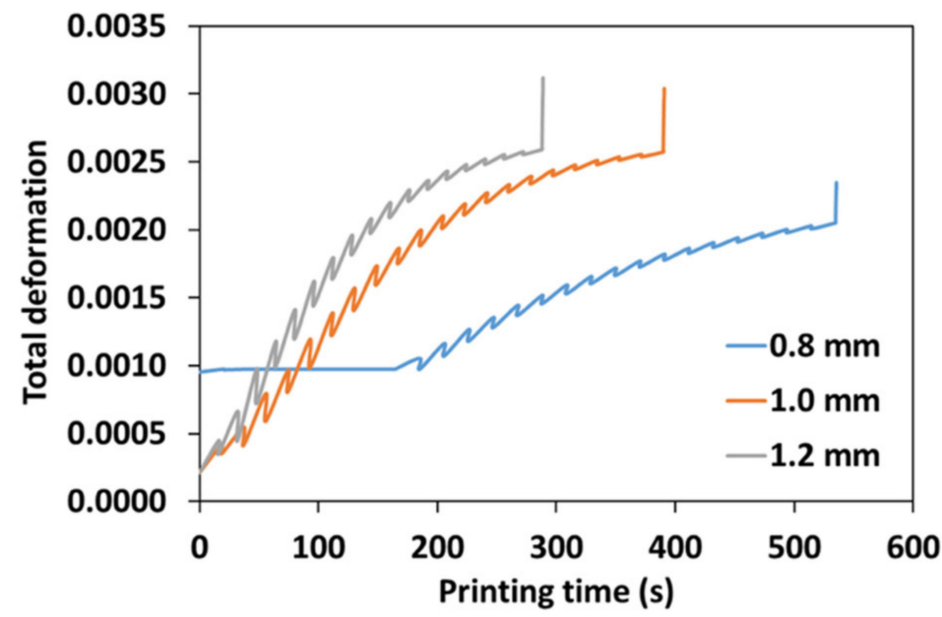

Figure 17. Total perpendicular deformation in a controlled environment temperature (a), and after structure-printing completion dependent on nozzle diameter $(\mathbf{b})$.

Products printed with nozzle diameters 1.0 and $1.2 \mathrm{~mm}$, on the other hand, showed a continuous increase in deformation until the completion of the printing process. The high value obtained for the $1.2 \mathrm{~mm}$ model was due to the increased flow rate with limited relaxation time. This is also connected to the increased stress value seen in Figure 16. In addition, the deformation soon increased to 0.003 with nozzle diameter $1.2 \mathrm{~mm}$ with more printed layers (the component part highlighted in red in Figure 17), particularly at the structure edges (Figure 17a). According to the simulation results from the flow field distribution analysis and the elastic properties analysis, it is possible to infer that printing rice pastes (100:80) with a $1.0 \mathrm{~mm}$ nozzle diameter in a controlled temperature environment $\left(47 \pm 5^{\circ} \mathrm{C}\right)$ is the optimum choice. 


\subsection{Validation of Simulation Result by Printing Process and Image Analysis}

The front view images of the printed structures using the numerical simulation conditions are shown in Figure 18. The width and height of the printed product differ significantly from the design when printing with $0.8 \mathrm{~mm}$ and $1.2 \mathrm{~mm}$ nozzle diameter (Table 7). The best printing conditions are predicted to provide a product that is closer to the design (height $=20 \mathrm{~mm}$, breadth $=20 \mathrm{~mm}$ ). Similar to the additive simulation study in Section 3.5.5.5, the lower layers had greater deformations (Figure 18). The deformation observed at lower regions of the product could also result from the die swell ratio, increased pressure at the nozzle exit, or a high flow rate when using nozzle size $1.2 \mathrm{~mm}$. Thus, the area increased with increasing nozzle diameter (Table 7). In addition, the nozzle diameter affected surface smoothness. Figure 18 shows that the structure printed with nozzle diameter $1.0 \mathrm{~mm}$ had smooth surfaces, but those printed with 0.8 and $1.2 \mathrm{~mm}$ nozzle diameters had surface roughness. According to the viscoelastic simulation study, pressure and shear rate increased significantly at the nozzle exit, with a decrease in nozzle diameter; this may be a significant cause of the rough surface seen in the structures printed with $0.8 \mathrm{~mm}$; however, the surface roughness in the structure printed with the $1.2 \mathrm{~mm}$ size may have resulted from the high flow rate and short printing time. A similar finding was found during the AM of surimi paste due to increased pressure at the nozzle tip [23,39].

Nozzle $0.8 \mathrm{~mm}$

After printing $\left(47 \pm 5^{\circ} \mathrm{C}\right)$

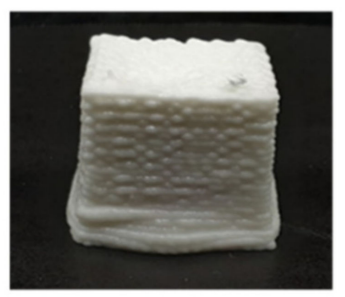

Nozzle $1.0 \mathrm{~mm}$
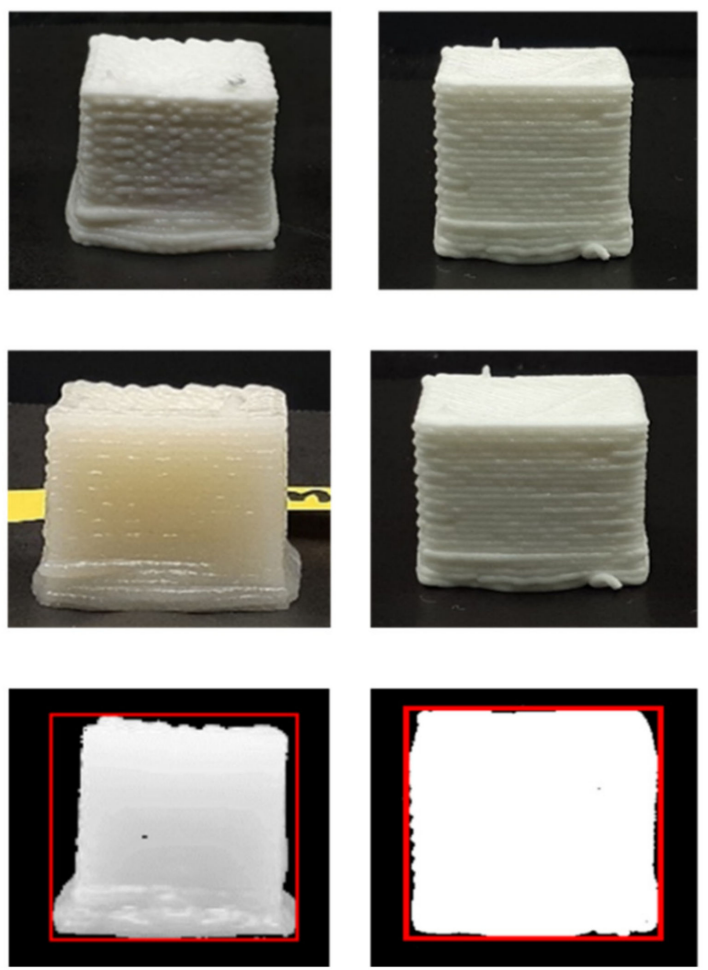

Nozzle $1.2 \mathrm{~mm}$
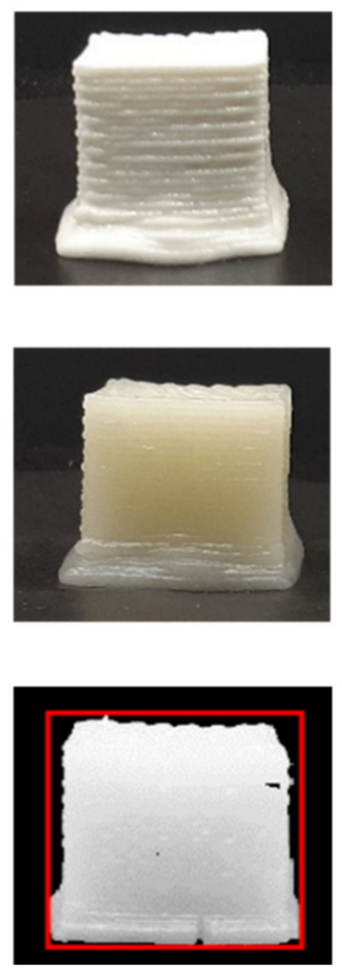

Figure 18. The 3D-printed rice paste with various nozzle diameters $(0.8,1.0$, and $1.2 \mathrm{~mm})$ before and after steaming.

Table 7. Image analysis of the printed rice paste model.

\begin{tabular}{cccc}
\hline Product Dimension $(\mathbf{m m})$ & Nozzle $\mathbf{0 . 8} \mathbf{~ m m}$ & Nozzle $\mathbf{1 . 0} \mathbf{~ m m}$ & Nozzle $\mathbf{1 . 2} \mathbf{~ m m}$ \\
\hline Height & $17.9 \pm 1.2^{\mathrm{b}}$ & $19.8 \pm 0.2^{\mathrm{a}}$ & $16.8 \pm 1.3^{\mathrm{b}}$ \\
Width & $22.8 \pm 0.08^{\mathrm{b}}$ & $20.2 \pm 0.9^{\mathrm{a}}$ & $23.1 \pm 1.6^{\mathrm{b}}$ \\
Area & $38.4 \pm 0.7^{\mathrm{a}}$ & $39.2 \pm 0.8^{\mathrm{a}}$ & $42.8 \pm 1.3^{\mathrm{b}}$ \\
\hline
\end{tabular}

Means \pm SD with superscript letters (a and b) along same row are significantly different at $p<0.05$. 
Furthermore, an edible gel must be formed from the printed structure without producing substantial modifications to the printed object's shape. Consequently, printed samples were steamed for $40 \mathrm{~min}$ at $80^{\circ} \mathrm{C}$, and the results revealed no significant differences in the postprinting and poststeaming processes (Figure 18). Based on these findings, it was concluded that printing rice paste (100:80) with nozzle diameters of $1.0 \mathrm{~mm}$ will result in a reasonable dimensional resolution and surface quality closer to the designed model (Figure 18).

\section{Conclusions}

This study presented a logical method for evaluating the additive manufacturing and deposition process of rice paste using CFD modeling. The rheological result demonstrated that the rice paste (100:80) is ideal for printing. The ambient temperature influenced the stability and slumping behavior of the printed product. Structural collapse improved with an increase in printing environment temperature $\left(47 \pm 5^{\circ} \mathrm{C}\right)$. The viscoelastic properties of the printer chamber showed that pressure, velocity, shear rate, and extrudate die swell are influenced by the printing process. An increase in nozzle diameter from 0.8 to $1.2 \mathrm{~mm}$ resulted in a decrease in the paste velocity $\left(0.185\right.$ to $\left.0.083 \mathrm{~ms}^{-1}\right)$, shear rate ( 952.75 to $\left.300.96 \mathrm{~s}^{-1}\right)$, and pressure $\left(-1.532 \times 10^{7} \mathrm{~Pa}\right.$ to $\left.-5.485 \times 10^{6} \mathrm{~Pa}\right)$. Similarly, the die swell ratio of the extrudate showed a decreasing ratio (15.15 to $13.73 \%$ ) with an increase in nozzle diameter; thus reducing the high deformation recorded when printing with a smaller nozzle size. The AM simulation revealed that the temperature distribution, residual stress, and total deformation of the sample is dependent on the nozzle diameter. A small nozzle diameter $(0.8 \mathrm{~mm})$ resulted in significantly higher deformation $(0.001)$ from the beginning of the printing process until $178.3 \mathrm{~s}$, which resulted from the high shear rate, pressure, and die swell effect at the nozzle tip. The image analysis result of the printed product agrees with viscoelastic and AM simulation; therefore, CFD modeling before the printing process could be an effective tool for analyzing the deposition and printing process of rice paste and may be extended to other types of foods.

Author Contributions: Conceptualization, T.M.O. and W.B.Y.; Methodology, T.M.O. and W.B.Y.; Investigation, T.M.O.; Writing-original draft preparation, T.M.O.; Writing-review and editing, T.M.O. and W.B.Y.; Supervision, W.B.Y.; Project administration, W.B.Y. All authors have read and agreed to the published version of the manuscript.

Funding: This research was funded by the Korea Institute of Planning and Evaluation for Technology in Food, Agriculture, and Forestry (IPET) through the Agro and Livestock Products Safety Flow Management Technology Development Program (grant number: 318079-2), and the IPET was funded by Ministry of Agriculture, Food and Rural Affairs (MAFRA). This research was supported by Basic Science Research Program through the National Research Foundation of Korea (NRF) funded by the Ministry of Education (2018R1D1A3B06042501).

Institutional Review Board Statement: Not applicable.

Informed Consent Statement: Not applicable.

Data Availability Statement: The data presented in this study are available on request from the corresponding author. The data are not publicly available due to restriction in agreement with funding organization.

Conflicts of Interest: Hereby, all authors declare that there are no conflict of interest in this manuscript.

\section{References}

1. Oyinloye, T.M.; Yoon, W.B. Stability of 3D printing using a mixture of pea protein and alginate: Precision and application of additive layer manufacturing simulation approach for stress distribution. J. Food Eng. 2021, 288, 110127. [CrossRef]

2. Oyinloye, T.M.; Yoon, W.B. Application of Computational Fluid Dynamics (CFD) Simulation for the Effective Design of Food 3D Printing (A Review). Processes 2021, 9, 1867. [CrossRef]

3. Yang, F.; Zhang, M.; Bhandari, B.; Liu, Y. Investigation on lemon juice gel as food material for 3D printing and optimization of printing parameters. LWT 2018, 87, 67-76. [CrossRef] 
4. Zhang, S.; Vijayavenkataraman, S.; Lu, W.F.; Fuh, J.Y. A review on the use of computational methods to characterize, design, and optimize tissue engineering scaffolds, with a potential in 3D printing fabrication. J. Biomed. Mater. Res. Part B Appl. Biomater. 2019, 107, 1329-1351. [CrossRef] [PubMed]

5. Guo, C.F.; Zhang, M.; Bhandari, B. A comparative study between syringe-based and screw-based 3D food printers by computational simulation. Comput. Electron. Agric. 2019, 162, 397-404. [CrossRef]

6. Mezi, D.; Ausias, G.; Grohens, Y.; Férec, J. Numerical simulation and modeling of the die swell for fiber suspension flows. J. Non-Newton. Fluid Mech. 2019, 274, 104205. [CrossRef]

7. Guo, C.; Zhang, M.; Devahastin, S. 3D extrusion-based printability evaluation of selected cereal grains by computational fluid dynamic simulation. J. Food Eng. 2020, 286, 110113. [CrossRef]

8. Qiu, C.; Li, P.; Li, Z.; Corke, H.; Sui, Z. Combined speed and duration of milling affect the physicochemical properties of rice flour. Food Hydrocoll. 2019, 89, 188-195. [CrossRef]

9. Kraithong, S.; Lee, S.; Rawdkuen, S. Physicochemical and functional properties of Thai organic rice flour. J. Cereal Sci. 2018, 79, 259-266. [CrossRef]

10. Liu, Y.; Tang, T.; Duan, S.; Qin, Z.; Zhao, H.; Wang, M.; Li, C.; Zhang, Z.; Liu, A.; Han, G.; et al. Applicability of rice doughs as promising food materials in extrusion-based 3D printing. Food Bioprocess Technol. 2020, 13, 548-563. [CrossRef]

11. Liu, Y.; Tang, T.; Duan, S.; Qin, Z.; Li, C.; Zhang, Z.; Liu, A.; Wu, D.; Chen, H.; Han, G.; et al. Effects of sodium alginate and rice variety on the physicochemical characteristics and 3D printing feasibility of rice paste. LWT 2020, 127, 109360. [CrossRef]

12. Chung, H.J.; Liu, Q.; Huang, R.; Yin, Y.; Li, A. Physicochemical properties and in vitro starch digestibility of cooked rice from commercially available cultivars in Canada. Cereal Chem. 2010, 87, 297-304. [CrossRef]

13. Liu, Q.; Zhang, N.; Wei, W.; Hu, X.; Tan, Y.; Yu, Y.; Deng, Y.; Bi, C.; Zhang, L.; Zhang, H. Assessing the dynamic extrusion-based 3D printing process for power-law fluid using numerical simulation. J. Food Eng. 2020, 275, 109861. [CrossRef]

14. Turabi, E.; Sumnu, G.; Sahin, S. Rheological properties and quality of rice cakes formulated with different gums and an emulsifier blend. Food Hydrocoll. 2008, 22, 305-312. [CrossRef]

15. Huang, M.S.; Zhang, M.; Bhandari, B. Assessing the 3D printing precision and texture properties of brown rice induced by infill levels and printing variables. Food Bioprocess Technol. 2019, 12, 1185-1196. [CrossRef]

16. Shand, P.J.; Ya, H.; Pietrasik, Z.; Wanasundara, P.K.J.P.D. Physicochemical and textural properties of heat-induced pea protein isolate gels. Food Chem. 2007, 102, 1119-1130. [CrossRef]

17. Albano, K.M.; Franco, C.M.; Telis, V.R. Rheological behavior of Peruvian carrot starch gels as affected by temperature and concentration. Food Hydrocoll. 2014, 40, 30-43. [CrossRef]

18. Konaganti, V.K.; Ansari, M.; Mitsoulis, E.; Hatzikiriakos, S.G. Extrudate swell of a high-density polyethylene melt: II. Modeling using integral and differential constitutive equations. J. Non-Newton. Fluid Mech. 2015, 225, 94-105. [CrossRef]

19. Mitsoulis, E.; Hatzikiriakos, S.G. Annular extrudate swell of a fluoropolymer melt. Int. Polym. Process. 2012, 27, 535-546. [CrossRef]

20. Miri, A.K.; Mongrain, R.; Chen, L.X.; Mongeau, L. Quantitative assessment of the anisotropy of vocal fold tissue using shear rheometry and traction testing. J. Biomech. 2012, 45, 2943-2946. [CrossRef]

21. Huang, Y.; Tang, J.; Swanson, B.G.; Rasco, B.A. Effect of calcium concentration on textural properties of high and low acyl mixed gellan gels. Carbohydr. Polym. 2003, 54, 517-522. [CrossRef]

22. Oyinloye, T.M.; Yoon, W.B. Effects of Low-Temperature Drying with Intermittent Gaseous Chlorine Dioxide Treatment on Texture and Shelf-Life of Rice Cakes. Processes 2020, 8, 375. [CrossRef]

23. Wang, L.; Zhang, M.; Bhandari, B.; Yang, C. Investigation on fish surimi gel as promising food material for 3D printing. J. Food Eng. 2018, 220, 101-108. [CrossRef]

24. Jane, J.L.; Chen, Y.Y.; Lee, L.F.; McPherson, A.E.; Wong, K.S.; Radosavljevic, M.; Kasemsuwan, T. Effects of amylopectin branch chain length and amylose content on the gelatinization and pasting properties of starch. Cereal Chem. 1999, 76, 629-637. [CrossRef]

25. Chaisawang, M.; Suphantharika, M. Pasting and rheological properties of native and anionic tapioca starches as modified by guar gum and xanthan gum. Food Hydrocoll. 2006, 20, 641-649. [CrossRef]

26. Tabilo-Munizaga, G.; Barbosa-Cánovas, G.V. Rheology for the food industry. J. Food Eng. 2005, 67, 147-156. [CrossRef]

27. Derycke, V.; Vandeputte, G.E.; Vermeylen, R.; De Man, W.; Goderis, B.; Koch, M.H.J.; Delcour, J.A. Starch gelatinization and amylose-lipid interactions during rice parboiling investigated by temperature resolved wide angle $X$-ray scattering and differential scanning calorimetry. J. Cereal Sci. 2005, 42, 334-343. [CrossRef]

28. Resio, A.C.; Suarez, C. Gelatinization kinetics of amaranth starch. Int. J. Food Sci. Technol. 2001, 36, 441-448. [CrossRef]

29. Spigno, G.; De Faveri, D.M. Gelatinization kinetics of rice starch studied by non-isothermal calorimetric technique: Influence of extraction method, water concentration and heating rate. J. Food Eng. 2004, 62, 337-344. [CrossRef]

30. Meerts, M.; Cardinaels, R.; Oosterlinck, F.; Courtin, C.M.; Moldenaers, P. The impact of water content and mixing time on the linear and non-linear rheology of wheat flour dough. Food Biophys. 2017, 12, 151-163. [CrossRef]

31. Liu, Z.; Zhang, M.; Bhandari, B.; Wang, Y. 3D printing: Printing precision and application in food sector. Trends Food Sci. Technol. 2017, 69, 83-94. [CrossRef]

32. Zhang, M.; Vora, A.; Han, W.; Wojtecki, R.J.; Maune, H.; Le, A.B.; Thompson, L.E.; McClelland, G.M.; Ribet, F.; Engler, A.C.; et al. Dual-responsive hydrogels for direct-write 3D printing. Macromolecules 2015, 48, 6482-6488. [CrossRef] 
33. Liu, Z.; Bhandari, B.; Prakash, S.; Mantihal, S.; Zhang, M. Linking rheology and printability of a multicomponent gel system of carrageenan-xanthan-starch in extrusion based additive manufacturing. Food Hydrocoll. 2019, 87, 413-424. [CrossRef]

34. Yang, F.; Guo, C.; Zhang, M.; Bhandari, B.; Liu, Y. Improving 3D printing process of lemon juice gel based on fluid flow numerical simulation. LWT 2019, 102, 89-99. [CrossRef]

35. Liu, Y.; Liang, X.; Saeed, A.; Lan, W.; Qin, W. Properties of 3D printed dough and optimization of printing parameters. Innov. Food Sci. Emerg. Technol. 2019, 54, 9-18. [CrossRef]

36. Sombatsompop, N.; Dangtangee, R. Effects of the actual diameters and diameter ratios of barrels and dies on the elastic swell and entrance pressure drop of natural rubber in capillary die flow. J. Appl. Polym. Sci. 2002, 86, 1762-1772. [CrossRef]

37. Mahapatra, A.K.; Lan, Y.; Harris, D.L. Influence of moisture content and temperature on thermal conductivity and thermal diffusivity of rice flours. Int. J. Food Prop. 2011, 14, 675-683. [CrossRef]

38. Horabik, J.; Molenda, M. Parameters and contact models for DEM simulations of agricultural granular materials: A review. Biosyst. Eng. 2016, 147, 206-225. [CrossRef]

39. Vogeler, F.; Verheecke, W.; Voet, A.; Valkenaers, H. An initial study into Aerosol Jet ${ }^{\circledR}$ printed interconnections on extrusion based 3D printed substrates. Stroj. Vestn. J. Mech. Eng. 2013, 59, 689-696. [CrossRef] 